\title{
Aptamers for pharmaceuticals and their application in environmental analytics
}

\author{
Beate Strehlitz • Christine Reinemann • \\ Soeren Linkorn • Regina Stoltenburg
}

Received: 27 July 2011 /Accepted: 10 November 2011 /Published online: 17 December 2011

(C) The Author(s) 2011. This article is published with open access at Springerlink.com

\begin{abstract}
Aptamers are single-stranded DNA or RNA oligonucleotides, which are able to bind with high affinity and specificity to their target. This property is used for a multitude of applications, for instance as molecular recognition elements in biosensors and other assays. Biosensor application of aptamers offers the possibility for fast and easy detection of environmental relevant substances. Pharmaceutical residues, deriving from human or animal medical treatment, are found in surface, ground, and drinking water. At least the whole range of frequently administered drugs can be detected in noticeable concentrations. Biosensors and assays based on aptamers as specific recognition elements are very convenient for this application because aptamer development is possible for toxic targets. Commonly used biological receptors for biosensors like enzymes or antibodies are mostly unavailable for the detection of pharmaceuticals. This review describes the research activities of aptamer and sensor developments for pharmaceutical detection, with focus on environmental applications.
\end{abstract}

Keywords Aptamer-Small organic molecule .

Pharmaceutical $\cdot$ Biosensor $\cdot$ Environmental analysis

B. Strehlitz $(\triangle) \cdot$ C. Reinemann $\cdot$ S. Linkorn $\cdot$ R. Stoltenburg UFZ-Helmholtz Centre for Environmental Research,

Permoserstr. 15,

04318 Leipzig, Germany

e-mail: beate.strehlitz@ufz.de

\section{Introduction}

Aptamers

Even though, until now, aptamers have been developed mainly for medical applications or clinical diagnostics, they are well suited as novel biological recognition elements for the detection of pharmaceutical residues in the environment because of their specific properties. Aptamers are short single-stranded oligomers (ssDNA or RNA), which are able to bind their target molecules with high specificity and selectivity. Binding occurs because of their specific and complex three-dimensional shape characterized by stems, loops, bulges, hairpins, pseudoknots, triplexes, or quadruplexes. The aptamer-target binding results from structure compatibility, stacking of aromatic rings, electrostatic and van der Waals interactions, and hydrogen bondings, or from a combination of these effects $[1,2]$.

Initially, RNA aptamer development was described for bacteriophage T4 DNA polymerase [3] and organic dyes Cibacron blue and Reactive blue 4 [4]. These publications described for the first time the evolutionary process to select aptamers starting with of a big variety of oligonucleotides in a so-called library (ca. $10^{15}$ different structures) by repeated rounds consisting of the steps (a) binding between target molecule and library, (b) elution of the bound oligonucleotides, and (c) their amplification. The resulting pool of pre-selected oligonucleotides forms the starting pool of the following round. This process is called systematic evolution of ligands by exponential enrichment (SELEX) and mimicks the Darwinian principle. The first DNA aptamers were described only 2 years later for Cibacron blue, Reactive blue 4, and Reactive green 19 [5]. 
Since then, aptamers for very diverse targets of different molecule classes and sizes were developed. Proteins are the predominant aptamer selection targets, but aptamers are also described for larger targets like whole cells, viruses, and tissues, or smaller targets like small organic molecules [6]. The SELEX principle was modified with a lot of variations, and most of them have their own names. The process of aptamer selection with its variants is not in the focus of this review. To get an overview, the reader is referred to our former review article [2] and similar articles [7-10].

One of the biggest advantages of aptamers in comparison to other biological recognition elements is the possibility to develop them for toxic substances as the frequently used biological recognition elements enzymes and antibodies cannot be developed for toxic targets. Pharmaceuticals are shown to have poisonous effects at least when used in high doses. Therefore, the development of antibodies for pharmaceuticals is a difficult thing to deal with. Aptamers are described for a great variety of pharmaceuticals with medical application. Some of them are used in detection systems but are mostly utilized for the measurement in blood or other body fluids. A new application field for aptamers is the detection of pharmaceutical residues in the environment, which have to be determined in a fast and simple way. On the other hand, aptamers can be pharmaceuticals by themselves. These aptamer therapeutics are used because of the high affinities to their target and specificities comparable to those of monoclonal antibodies for therapeutical treatments [11]. The most successful therapeutic application of an aptamer has been the adaptation of an antivascular endothelial growth factor aptamer [12]. The PEGylated form of this aptamer (called pegaptanib) is used as the medicinal active component in a drug for treatment of age-related wet macular degeneration. The pharmaceutical product Macugen ${ }^{\circledR}$ (pegaptanib sodium injection) from Pfizer Inc./OSI Pharmaceuticals was approved in December 2004 (USA) and January 2006 (Europe) [11, 13-15]. Aptamer therapeutics will not be reviewed in this paper. The focus of our examination lies on aptamers able to bind to pharmaceuticals, which are used for human and animal treatment and can be found in surface and ground waters as well as in drinking water. Pesticides are another group of water pollutants, identified as an environmental problem much earlier than pharmaceuticals. They are not considered in this review.

Pharmaceuticals in the environment

Pharmaceuticals belong to the trace contaminants in water which are large in number, low in quantity, huge in interference, and high in toxicity and presenting high challenges for detection on site and in real time [16]. The enormous amount of about $95 \%$ of the pharmaceuticals administered to humans is excreted unchanged or as decomposition or conversion product in urine or stool. Additionally, the disposal of leftover pharmaceuticals via toilet or sink is still going strong. By this way, human pharmaceuticals reach the wastewater treatment plants over the path of the wastewater. Common wastewater filter technologies do not remove all of the pharmaceutical residues, which finally arrive at the surface water bodies. A total of $95 \%$ of the pharmaceuticals found in the environment derive from the treatment of humans and 5\% of animals [17]. The pharmaceuticals for animal treatment often go directly to the soil with the urine of grazing animals or by fertilization using stall manure and liquid manure and drain away into the ground water or by surface runoff into conterminous water bodies.

Although the pharmaceutical residues in the water cycle are mostly in the range of nanograms or micrograms per liter, the implications of this presence are mainly unknown. Anyhow, aquatic plants and animals are exposed to the pharmaceutical residues during their whole life time. Endocrine-disrupting substances in lakes and rivers, for instance, lead to feminization of male fish [18].

Drinking water is often made from ground and surface water (in Germany $76.2 \%$ ground water, $13.3 \%$ surface water, $10.5 \%$ others like bank filtrate) [19]. In this way, pharmaceutical residues are directly imbibed by humans but also enter the food and beverage industry. The entry of antibiotics into the environment can lead to antibiotic resistances. Infections of humans and animals with resistant bacteria are life-threatening because they can no longer be treated with antibiotics. Although the concentration of most pharmaceuticals in drinking water is below therapeutic doses and below the threshold values, the consequences to human health of a permanent uptake of pharmaceuticals in smallest amounts are still not investigated [20].

Aptamer-based systems for measurement, enrichment, and elimination of pharmaceuticals

Aptamers can act as specific affinity binders to target molecules. Their application is comparable to antibodies. Aptamers developed for pharmaceuticals can be used as biological receptors in assays, test systems, or biosensors for the measurement of these pharmaceuticals in solutions [21]. Moreover, they can be used for the enrichment of the target substances, especially before measurements in solutions with very low concentrations. Filtration and elimination of target substances out of a water matrix is possible by the application of aptamers [22].

The fast and easy detection of pharmaceutical residues may help to differentiate between unpolluted and polluted water regarding surface, ground, and drinking water. 
Appropriate aptamer-based measuring systems may be used for:

- Automatic monitoring of the functionality of wastewater treatment plants regarding pharmaceutical degradation

- Analysis of immission pathways of pharmaceuticals into the environment

- Construction of components of wastewater treatment plants, like filters, to test the filtration effect using markers

- Inspection of incoming components, like the raw material "water" (production water as well as drinking water) in the food production

Very important for all these aptamer applications are their special properties such as reversible binding and reversible folding which enables regeneration of the aptamer-target binding.

Until now, standard methods for the determination of pharmaceuticals are based mainly on methods like highperformance liquid chromatography, gas chromatography (GC), GC coupled with mass spectroscopy, or liquid chromatography coupled with mass spectroscopy. All these methods are laborious, time-consuming, and need highly skilled personnel. Aptamer-based systems for pharmaceuticals detection would offer an alternative for fast and easy detection of the substances. Moreover, when the aptamers are coupled with very easy detection systems (for instance colorimetric assays), an in-field screening of the relevant substance in environmental samples would be possible. Below, recent developments of RNA aptamers and their properties are presented.

\section{RNA aptamers for pharmaceuticals}

Most of the investigations on RNA-drug interactions are dedicated to antibiotics. Emerging bacterial resistances for existing antibiotics pose a constant threat to human health. In order to develop new drugs by a rational approach, it is necessary to gain detailed knowledge of the mode of action of existing antibiotics. Numerous antibiotics are known to interact with different functional RNA species like rRNA [23, 24], self-splicing introns [25], and hammerhead ribozymes [26]. These interactions obstruct the normal function of the respective RNA and associated molecules. However, a detailed understanding of the underlying principles that govern the molecular recognition between antibiotics and RNA is lacking. Characterization of the full length of naturally occurring RNA is rather tedious or even unfeasible. So small binding RNA aptamers that are more amenable to structural characterization are used as an elegant alternative. These studies contribute plenty of information on how different RNAs are able to bind to small molecules. In contrast to antibiotics, the interactions between RNA and other classes of molecules such as psychotropics are only infrequently examined. Although modifications that render RNA aptamers more stable to environmental conditions can be easily introduced, the application as molecular recognition elements is more an exception than the rule. This field of application is relinquished to the more suited DNA aptamers.

RNA aptamers for aminoglycoside antibiotics

\section{Tobramycin}

In order to investigate small RNA structures that are able to recognize aminoglycosides, RNA capable of binding to tobramycin was identified using an in vitro SELEX approach [27]. After six cycles of selection, 18 clones were sequenced. All of the clones were unique showing no obvious consensus sequence. Clone W13 bound to a single tobramycin molecule with a dissociation constant of $3.0 \mu \mathrm{M}$. The pool from the sixth round was subjected to additional seven selection cycles. From the new pool, two classes of consensus sequences with substantial sequence homology were obtained. From each class, one representative (X1 and J6) was chosen for further study. Both sequences displayed an additional high affinity binding site resulting in a 2:1 stoichiometry between tobramycin and the aptamers. The $K_{\mathrm{D}}$ values for the binding to the high affinity sites were $2 \mathrm{nM}$ for $\mathrm{J} 6$ and $3 \mathrm{nM}$ for X1, respectively, whereas the corresponding $K_{\mathrm{D}}$ values for the low affinity sites were $6 \mu \mathrm{M}$ for $\mathrm{J} 6$ and $16 \mu \mathrm{M}$ for $\mathrm{X} 1$. The consensus sequences were predicted to form stem-loop structures which in turn were expected to constitute the binding regions. Minimal structures truncated to the stem-loop motifs (X1sl and J6sl) confirmed a 2:1 binding stoichiometry. The high affinity binding sites were shown to have slightly reduced affinities for tobramycin compared to the originally selected aptamers.

In a subsequent study X1, J6 and an additional X3 sequence were characterized in more detail [28]. The predicted stem-loop structures were confirmed to be the tobramycin binding regions. Competition experiments with neomycin, gentamicin, and erythromycin revealed affinities that were three to six orders of magnitude lower for these molecules than for tobramycin. NMR solution structures of related versions of the selected aptamers confirmed the stem-loop structures as the tobramycin binding sites and provided a detailed picture of the specifics of the binding [29, 30].

A simplified 39-mer version of J6 termed J6e with a dissociation constant of $58 \mathrm{nM}$ discriminated between similar aminoglycosides as well [31]. A trinucleotide bulge 
in the stem of the structure turned out to be essential for binding. Substitutions that resulted in a shortening of the loop were not tolerated.

Investigation of yet another J6-related sequence (J6f1) showed that tobramycin is recognized by the bases of the aptamer and does not interact with the phosphate backbone [32]. The trinucleotide bulge is not directly involved in the recognition of tobramycin but is necessary to pry open the double helical region in order to allow tobramycin to access the bases of the aptamer.

Aptamers for tobramycin that could be converted into beacon aptamers were selected using a selection process designed to obtain sequences that undergo a conformational change upon the binding of tobramycin [33]. Two sequence families were obtained after 14 selection cycles. These sequences were unrelated to the previously selected aptamers [27]. One clone from each family was converted into a beacon aptamer (BA14-1 and BA14-2). Increase in fluorescence intensity upon tobramycin binding was found to be modest but reproducible. $K_{\mathrm{D}}$ values were approximately $16 \mu \mathrm{M}$ for BA14-2 and $500 \mu \mathrm{M}$ for BA14-1. Paromomycin was shown to exhibit no response.

A new selection cycle using a partially randomized version of the previously selected BA14-2 aptamer [33] as a starting point was carried out by Vandenengel and Morse [34]. A mutational variant of BA14-2 termed A415256 showed a five times lower minimal detection limit $(2 \mu \mathrm{M})$ for tobramycin compared to the original BA14-2 $(10 \mu \mathrm{M})$. The detection limit for kanamycin $\mathrm{B}$ was determined to be $30 \mu \mathrm{M}$ but with a significantly decreased efficiency. Kanamycin A was barely detectable at $30 \mu \mathrm{M}$ whereas amikacin and paromomycin showed no response.

\section{Neomycin B}

Neomycin B binds to different RNA targets including 16S rRNA, the group I intron, and the hammerhead ribozyme. One possible explanation for this behavior is that these RNA structures share a common structural motif.

In order to identify structural requirements for neomycin B binding, small RNA sequences suited for neomycin B binding were isolated by in vitro selection [35]. Eight rounds of selection resulted in 21 aptamer clones which shared a 13-nucleotide consensus sequence in approximately half of the cases. The conserved region folded into a stem-loop structure. The loop consisted of a five base consensus sequence whereas the stems varied in sequence and in length. However, sequences that did not share the consensus sequence folded into stem-loop structures as well. The overall stem-loop structure could be confirmed to provide the neomycin B binding site. The $K_{\mathrm{D}}$ value for the clone neo5 was determined to be $115 \mathrm{nM}$. The related paromomycin bound with a 100 times lower affinity. Binding of the aptamer to neomycin B was found to be $\mathrm{Mg}^{2+}$ dependent. Based on the facts that neomycin B was recognized by different selected RNA molecules with variations in the consensus sequence and that no consensus sequence was found compared to natural occurring RNA, the authors concluded that the molecular three-dimensional shape of the RNA molecules is the crucial factor for neomycin $\mathrm{B}$ binding rather than a specific RNA sequence.

Details of the molecular recognition between the aptamers and neomycin B were investigated by other research groups. The NMR structure of a complex between a 23-mer version of the selected aptamers and neomycin B revealed that the rings I and II of the neomycin B molecule are anchored within a RNA binding pocket [36]. Binding of neomycin to this pocket is governed by hydrogen bonding [37]. The directional characteristics of hydrogen bonds provide an explanation of the observed variations in affinities of aptamers for aminoglycosides that differ slightly in stereochemistry and in the position of their functional groups. Two additional low affinity binding sites could be discovered using spectroscopic methods [38]. These sites are nonspecific and result from electrostatic interactions between the RNA backbone and the neomycin molecule.

An additional selection using a different selection scheme was successfully carried out providing further insights into sequence requirements for neomycin B binding [39]. Five rounds of selection using a pool including a 47-nucleotide sequence from the 16S rRNA with $30 \%$ degeneracy per position were successful in yielding binding sequences for neomycin B. The selected sequences were no longer able to fold into the wild-type secondary structure (motif A). Sequences corresponding to the consensus sequence folded into the same hairpin motif (motif B) as the previously selected aptamers that were obtained using a completely randomized library [35]. The dissociation constant for a motif B aptamer (clone22) was determined to be $0.5 \mu \mathrm{M}$. Motif $\mathrm{A}$ sequences were shown to have lower affinities. The selection showed that optimized sequences for neomycin B that bind with higher affinities compared to natural occurring RNA can be readily obtained by in vitro selection.

\section{Kanamycin A}

An evolutionary relationship between naturally occurring functional RNA molecules would provide an explanation for the observed interactions of aminoglycoside antibiotics with diverse functional RNA. In order to estimate the 
diversity of RNA sequences that are able to bind to the aminoglycoside antibiotic kanamycin A (and lividomycin, see below), an in vitro selection was performed by Lato et al. [40]. Four selection cycles resulted in an RNA pool that was estimated to contain approximately $10^{6}$ different sequences for kanamycin A binding. Because of this great number, only a spot check of individual sequences was possible. No duplications and obvious sequence motifs could be recognized. Secondary structure predictions revealed a multitude of single and multiple stem-loops, internal loops, multiarm junctions, and stems with or without bulges. A predominant motif was not observed. Affinity elution was used to determine binding constants which were estimated to be no more than $220 \mathrm{nM}$. Specificity tests showed that members of the kanamycin family (dibekacin and amikacin) bind tighter to the selected RNA than the less similar ribostamycin or the unrelated streptomycin. Although kanamycin A and kanamycin B differ only by one amino group, some of the selected sequences were able to distinguish between these molecules. Comparison to aminoglycoside binding sites on naturally occurring RNA species exhibited no structural similarities despite of the functional similarities. The authors concluded from the fact that there is a multitude of structures for kanamycin A binding that different unrelated RNA species could have evolved to bind to aminoglycosides, and therefore, a single RNA ancestor for today's functional RNA molecules is rather unlikely. This conclusion seems to be open for discussion. Four rounds of selection may not be sufficient to effectively narrow down the pool to the best binding sequences. A small subset of high affinity binders may be hidden in the highly divergent pool and is most likely to be missing in the characterization procedures. Therefore, potential similarities to natural occurring RNA structures are very likely to escape the notice of the authors.

\section{Kanamycin B}

To gain insight into the general rules that govern the recognition between RNA and different aminoglycoside antibiotics, kanamycin $\mathrm{B}$ was chosen as a target for in vitro selection [41]. Kanamycin B was considered to be a promising target because it differs only by an additional hydroxyl group from tobramycin for which tightly binding aptamers were already selected [27]. Twelve clones from the ninth selection cycle were investigated. Three sequences were found to be identical, but no further sequence homology with the remaining sequences was discovered. The triplicated RNA (K8) was the best binding sequence with a $K_{\mathrm{D}}$ of $180 \mathrm{nM}$. K8 was able to discriminate between kanamycin B and paromomycin by a factor of approximately 10. The dissociation constant for kanamycin A was 4.4 $\mu \mathrm{M}$ suggesting an important role for the 2-amino group in the A-ring of kanamycin B for the target recognition. Tobramycin was found to bind even tighter to $\mathrm{K} 8\left(K_{\mathrm{D}}=\right.$ $11.6 \mathrm{nM}$ ) compared to the actual selection target kanamycin B. Secondary structure prediction of $\mathrm{K} 8$ revealed a molecule composed of stem-loop structures containing several bulges. A 22-nucleotide minimal version was predicted to form a short stem with a bulge and a loop at the 5 '-end of the aptamer. A non-canonical base pair was suggested to lead to a widening of the groove that hosts the aminoglycoside. The identities of the bases in the loop were found to be essential for aminoglycoside binding.

\section{Lividomycin}

In the same study that was performed to select aptamers for kanamycin A (see above), lividomycin was an alternative target to explore if different functional RNA species are descendants of a common ancestor [40]. Four selection cycles revealed a large variety of binding sequences without any recognizable conserved sequences or secondary structure motifs. Six binding sequences were chosen for further investigation. Specificity was evaluated using related and unrelated aminoglycoside antibiotics. Members from the same family like neomycin and paromomycin were found to bind more tightly to the selected sequences than less similar molecules such as ribostamycin and kanamycin. $K_{\mathrm{D}}$ values of individual aptamers were found to be $300 \mathrm{nM}$ on average or less. The authors' conclusion that the obtained results suggest a multitude of different binding motifs for aminoglycoside antibiotics suffers from the same drawback mentioned in the kanamycin A paragraph. Four selection rounds are most likely inadequate to identify the best binding motifs so the conclusions drawn from the highly divergent fourth round pool may be inaccurate.

Another attempt including additional rounds of selection was performed to discover potential binding sites in naturally occurring RNA [42]. The selection was conducted in analogy to the original one [40], but six additional rounds with increased stringency were performed. In contrast to the previous selection, 12 of the 13 clones investigated were found to be identical. A stem-loop structure was predicted for the dominant species. Elements of the constant 3 '-region are involved in forming a long stem structure. Regrettably no truncation experiments were carried out, so it remains unclear if the invariable primer region is necessary for target binding. Comparison of the obtained sequence with genomic data revealed that the 
selected aptamer is similar to a part of the stomatitis virus. As apparent from this selection, the strategy to search for new potential targets for existing drugs rather than searching for new drugs seems to be a promising approach.

\section{Streptomycin}

Streptomycin interacts with ribosomal RNA and thereby interferes with translation. Inhibition of the self-splicing of group I intron RNA is also known. RNA sequences capable of binding streptomycin were selected to address the basic question how RNA molecules are able to bind to their respective ligand [43]. Four rounds of selection were performed before splitting the obtained pool. One part of the pool was subjected to three additional cycles. The other part was subjected to a counterselection step against bluensomycin followed by three cycles without counterselection. From the counterselection procedure, a 22nucleotide sequence (motif 1) without sequence variations was obtained. The procedure without any counterselection steps resulted in a 26-nucleotide sequence (motif 2) with sequence variations in only two bases. Three sequences that differed from motif 1 and motif 2 bound to streptomycin and suggested the formation of alternative binding motifs for the antibiotic. Minimal binding sequences for motif 1 and motif 2 consisted of 46 and 41 bases, respectively. The motif 1 minimer showed a strong discrimination between streptomycin and bluensomycin. This indicates that the single counterselection step was effective. The motif 2 minimer showed a lower affinity for streptomycin compared to the motif 1 minimer and bound to both antibiotics but had a preference for streptomycin. $\mathrm{Mg}^{2+}$ was shown to be an essential cofactor because no binding with either motif was detected in the absence of the ion. Conformational changes upon ligand binding in the presence of $\mathrm{Mg}^{2+}$ were observed for motif 1 but not for motif 2. Secondary structure prediction revealed two asymmetric internal loops separated by a stem. The structure is capped by a hairpin loop. No similarities to natural binding sites were found.

The X-ray structure of the binding complex showed that streptomycin is inserted in a pocket that includes elements from both asymmetric loops [44]. A total of three cation binding sites were suggested to stabilize an unusual conformation of the $5^{\prime}$-site.

RNA aptamers for tetracycline antibiotics

\section{Doxycycline}

Aptamers for the antibiotic doxycycline were selected exploiting the allosteric inhibition of a hammerhead ribozyme fused to a randomized RNA library [45]. Clones from cycles 10, 13, and 16 were sequenced. Eight different sequence classes were identified. After the cycles 10 and 13, an error-prone PCR step was introduced in order to increase the complexity of the enriched pool. The inhibition values $K_{i}$ for the four clones that showed the best inhibition is in the range of 20 to $70 \mathrm{nM}$. Specificity of the selected sequences was tested using tetracycline which differs only by one hydroxyl group from the original target doxycycline. Two clones showed an at least 10,000-fold discrimination between the two related substances. The two remaining clones exhibited a slightly enhanced discrimination of four to five times. The authors suggested the formation of a different binding pocket for these low discrimination sequences. The clone with the highest affinity (16-05) but with only modest discrimination abilities was subjected to further investigation in order to identify the minimal binding motif. A truncated sequence consisting exclusively of the randomized region was not sufficient for the binding to doxycycline. A helix domain of the fused hammerhead substructure was found to be a necessary component for the correct recognition of the target.

\section{Tetracycline}

Tetracycline interferes with the binding of the aminoacetyltRNA to the ribosomal A-site at the 30S ribosomal subunit and therefore inhibits the bacterial protein synthesis. Because the details of this interaction were poorly understood, a selection was performed with the aim to obtain aptamers against tetracycline with an affinity comparable to that of the small ribosomal subunit [46]. Binding sequences from round 13 and 14 were sequenced. The sequence $\operatorname{cb} 28$ was chosen for further analysis because its $K_{\mathrm{D}}$ value of $1 \mu \mathrm{M}$ was in the desired affinity range. The lead cleavage pattern suggested that the aptamer changes conformation upon ligand binding. In the absence of $\mathrm{Mg}^{2+}$, no binding was observed. Secondary structure prediction revealed an arrangement of several stems and loops. Some of them could be deleted without a loss of function. A minimal version of $\mathrm{cb} 28$ consisting of 60 nucleotides was predicted to form a stem-loop structure. Different tetracyclines were used to test the specificity of the aptamer. Class II tetracyclines which do not efficiently inhibit bacterial translation bound only poorly to cb28. Class I tetracyclines which inhibit prokaryotic translation bound with good affinities with the exception of doxycycline and minocycline. These findings suggested that the hydroxyl group at position 6 in the tetracycline molecule is a prerequisite for binding. A different binding mechanism for the aptamer and the ribosome was concluded. The authors suggested tetracycline binding to interhelical regions and accommodation in a three-way junction instead of the simple stem-loop motif usually observed for aminoglycoside antibiotic binding sites. The 
same motif could be identified in the selected ribozyme for the tetracycline antibiotic doxycycline [45].

The X-ray cocrystal structure of the cb28 minimer revealed the formation of a non-canonical pseudoknot [47]. The structure was stabilized by tetracycline and several tightly bound divalent cations. The antibiotic itself bound to the RNA as a magnesium chelate. This form of binding is known from tetracycline binding to the $30 \mathrm{~S}$ subunit of the bacterial ribosome as well. In comparison to other small molecule aptamers, the proposed three-helix junction is unique and similar to naturally occurring riboswitches.

\section{RNA aptamers for further antibiotics}

\section{Viomycin}

Viomycin is a small cyclic peptide antibiotic that interferes with prokaryotic protein synthesis as well as group I intron self-splicing. A selection of RNA sequences that bind to viomycin was conducted in order to investigate the molecular basis of the recognition of viomycin by RNA [48]. Seven rounds of selection resulted in 23 sequences. Only one of these sequences was selected multiple times. A stretch of 14 nucleotides showed a close relationship for different clones at the primary sequence level. Bases at both ends of this region were able to form base pairs. Accordingly, a stem-loop structure was proposed. Dissociation constants for sequences containing this consensus sequence were in the range of 11 to $21 \mu \mathrm{M}$. A truncated version consisting only of the conserved loop and a sixbase stem was not sufficient for viomycin binding. Additional investigations revealed that a shortage from the $3^{\prime}$-end of the aptamer was not tolerated. Bases located in this region have the potential to base pair with the conserved loop structure. This pairing results in the formation of a pseudoknot structure. Natural target sites of viomycin are proposed to fold into pseudoknot structures as well [49]. The authors concluded that viomycin has specificity for pseudoknot structures and is able to recognize particular pseudoknots.

\section{Linezolid}

Linezolid is an oxazolidinone antibiotic that interferes with bacterial protein synthesis by inhibition of the ribosomal function. A linezolid-neomycin conjugate was successfully used to select linezolid binding sequences from a genomic library [50]. Eight rounds of selection were performed, and three clones that were selected multiple times were chosen for further investigation. Structure prediction revealed a typical stem-loop motif. Dissociation constants of truncated versions of the selected aptamers binding to the hetero- conjugate were in the range of 66 to $260 \mathrm{nM}$. Neomycin which is part of the heteroconjugate bound with an affinity of about $300 \mathrm{nM}$. Due to the weak affinity of linezolid to the selected sequences, a direct binding could not be observed. Neomycin bound exclusively to the stem region. The binding of the heteroconjugate was extended to the terminal loop, and accordingly, this site was assigned to be the binding site for linezolid. Surface plasmon resonance (SPR) measurements using the strongest binding sequence (L2-12) resulted in an affinity of $5.4 \mathrm{mM}$ for linezolid. The affinity in the presence of neomycin was $0.45 \mathrm{mM}$ which supported the assumption of different binding sites for both molecules.

\section{Chloramphenicol}

Chloramphenicol inhibits the peptidyl transferase activity in prokaryotes by association with the 23S rRNA which is involved in the peptide bond formation. Recognition of chloramphenicol by RNA was studied investigating RNA molecules that are able to bind to the antibiotic [51]. Two libraries differing in the length of the random region were subjected to the selection procedure. After 12 rounds of selection, 96 aptamer clones were investigated of which 74 were shown to be unique. $K_{\mathrm{D}}$ values ranged from $200 \mu \mathrm{M}$ to less than $2 \mu \mathrm{M}$. The best binding sequences were the best represented sequences in the enriched pool. Nine sequences were predicted to fold into helices containing two asymmetric bulges formed by four to six adenosines located across a single adenosine. A minimal 50-nucleotide version containing both asymmetric bulges (Cam1) and a 33-nucleotide version containing only one asymmetric bulge (Cam2) were prepared. Cam1 had an affinity comparable to the full-length RNA whereas Cam2 showed no activity. Five additional rounds of selection using Cam1 with a $15 \%$ mutagenesis rate per position were performed. Domains that were supposed to form the binding sites such as the successive adenosines in the bulges were found to be invariant or nearly invariant. Reselection of a mutated version of Cam 2 showed activity after six rounds. No resemblance to the original Cam2 molecules was observed. The sequences seemed to have diverged to other binding motifs that were not further evaluated. NMR studies revealed a 1:1 stoichiometry between Cam1 and chloramphenicol. This result is rather surprising because chloramphenicol itself is not a symmetrical molecule. One explanation is that both binding sites might not be accessible at the same time. But the lack of activity of Cam2 contradicts this assumption. An alternative explanation is the formation of tertiary interactions between both of the adenosine elements that provide a single binding site. The authors proposed this as a mechanism for the chloramphenicol binding in the 23S rRNA where the formation of a similar structure would bring into contact three regions that are thought to be involved in chloramphenicol binding. 


\section{Moenomycin A}

Moenomycins inhibit the bacterial cell wall synthesis by interacting with the transglycosylase resulting in the prevention of chain elongation of the formed polysaccharide strand. One strategy to discover new drugs is to search for biosynthetic precursors of already existing drugs. In the next step, these precursors may be used to construct semisynthetic libraries which in turn are screened for active compounds [52]. Because there are no classical antibodies for derivatives of the antibiotic moenomycin A, a screening for RNA sequences that are able to bind to moenomycin A was performed [52]. A total of 12 selection cycles using three slightly different approaches resulted in approximately 100 clones to be investigated. The selected RNA molecules were dominated by two motifs. The invariable primer binding sites were shown to be not necessary for binding. Dissociation constants were determined to be in the range of 300 to $400 \mathrm{nM}$. Unfortunately, secondary structures were not examined so comparison to other small molecule binding RNA motifs is not possible. Competition assays demonstrated that the selected aptamers recognize the disaccharide portion of moenomycin A. Fluorescence correlation spectroscopy using a tetramethylrhodamine derivative of moenomycin was applied to study the formation of the RNA-moenomycin complex [53]. One representative of the previously selected aptamers [52] (A6) was shown to have a $K_{\mathrm{D}}$ value of $437 \mathrm{nM}$. This value is in good agreement with the $320 \mathrm{nM}$ for the same aptamer obtained using affinity chromatography.

RNA aptamers for pharmaceuticals with psychotropic effects

\section{Codeine}

Codeine is a constituent of opium and widely used as a narcotic drug but is often abused for its euphoric and depressant effects [54]. Possible applications of codeine binding aptamers in sensor systems or as tools for biotechnological purposes prompted Win et al. to select aptamers against codeine [55]. Fifteen selection cycles including three error-prone PCR steps in rounds 11 to 13 and a counterselection step against morphine yielded about 60 clones. Five identical sequences and two sets with one-nucleotide difference were identified. The remaining sequences were shown to be unique. A consensus sequence or structural similarity between the different sequences could not be observed, but short stretches of identical bases were found in many clones. Sequences with the highest affinities (FC5 and FC45) were chosen for further analysis. $K_{\mathrm{D}}$ values for binding in solution were $4.5 \mu \mathrm{M}$ for FC5 and $47 \mu \mathrm{M}$ for FC45. A higher specificity for codeine compared to morphine was reflected by lower affinities for morphine $(25 \mu \mathrm{M}$ for FC5 and $212 \mu \mathrm{M}$ for FC45). The successful molecular discrimination is based on a single methyl group by which codeine differs from morphine. FC5 showed a higher affinity for thebaine compared to codeine whereas FC45 had a higher affinity for codeine. The authors suggested that this behavior is a consequence of the immobilization procedure which allowed no presentation of differential functional groups. This in turn implies that the selected aptamers are able to recognize conformational differences between thebaine and codeine. A truncated 41nucleotide version of FC5 (FC5L) including the random region and the $5^{\prime}$ constant region exhibited an affinity for codeine comparable to the 59-nucleotide parent sequence. The analog 44 minimer of FC45 (FC45L) bound to codeine with an almost identical affinity as the original aptamer. The predicted structures of the minimal aptamers revealed stemloop structures which differed from other known stem-loop structures in the length of the stem region which is composed of only two to three base pairs. Modifications that extended the stems were tolerated as demonstrated by comparable affinities for codeine.

\section{Theophylline}

Theophylline is a naturally occurring alkaloid used in the treatment of asthma and bronchitis [56]. A theophylline aptamer was obtained by Jenison et al. after eight selection cycles [57]. A simultaneous selection introduced a counterselection step against the related caffeine in round five. A consensus secondary structural motif revealed a stem-loop structure which encompasses the binding region. An RNA sequence from the pool that was subjected to the counterselection against caffeine (TCT8-4) was chosen to determine the binding characteristics. The affinity to theophylline was determined to be $0.6 \mu \mathrm{M}$. No binding was detected in the absence of magnesium ions. A truncated version containing 38 nucleotides (mTCT8-4) was used to determine the minimal binding requirements. This minimal version showed an enhanced affinity of $0.1 \mu \mathrm{M}$. Caffeine and nine other xanthine derivatives were chosen for competition experiments. The affinities ranged from three times lower affinity for CPtheophylline to a 10,000 times lower affinity for caffeine. From these assays, the authors concluded that the N-7 hydrogen is essential for theophylline binding. NMR measurements showed a conformational change upon ligand binding and revealed a 1:1 stoichiometry between the selected aptamer and theophylline.

\section{Dopamine}

Dopamine is a catecholamine neurotransmitter which is supposed to play an essential role in degenerative disorders of the central nervous system culminating in diseases like schizophrenia [58], Huntington's disease [59], and Parkinson's 
disease [60]. RNA aptamers for dopamine were selected by Mannironi et al. [61]. After nine rounds of selection, 44 clones were sequenced and 20 of them were found to be identical. No sequence homology between the different clones could be observed so that various sequences of RNA that are able to bind to dopamine seem to exist. The most abundant clone dopa2 with an affinity of $2.8 \mu \mathrm{M}$ was chosen for further analysis. Secondary structure predictions showed an arrangement of four stem-loop motifs. Truncation at the 3 '-end eliminating one stem-loop and parts of another stem were tolerated without a loss of function. The $5^{\prime}$-end including the invariable primer region was necessary for target binding. This truncated version termed dopa2/c.1 showed an increased affinity $(1.6 \mu \mathrm{M})$ compared to the parent aptamer. Binding experiments with various dopamine analogs indicated that the aliphatic chain and the hydroxyl group at position 3 are essential for the ligand-target recognition. Six additional rounds using a pool of partially randomized versions of dopa2 were performed. Sequence comparison between the original and the reselected sequences hinted at tertiary interactions between two of the loop structures. The binding pocket was proposed to be formed by canonical or wobble base pairing between the two loop structures. For the correct folding of the aptamer, magnesium ions were found to be essential. The minimal binding sequence had a length of 57 nucleotides which is relatively large compared to aptamers selected for other small molecules. RNA sequences that are able to bind to this neurotransmitter were successfully selected although there are no known interactions between nucleic acids and dopamine in vivo.

The described RNA aptamers are almost exclusively used as tools for the unraveling of molecular recognition processes occurring between functional RNA molecules and antibiotics. The required structural information can be more easily assessed for small RNA aptamers compared to the large natural RNAs. Stem-loop structures seem especially suited for the accommodation of aminoglycoside antibiotics. RNA aptamers for antibiotics that do not belong to the aminoglycoside class exhibit alternative structural motifs like pseudoknot structures (viomycin), asymmetric bulges connected by a stem (chloramphenicol), or a threehelix junction (doxycycline).

Furthermore, RNA aptamers can be successfully converted into beacon aptamers which respond with enhanced fluorescence intensity to the presence of the respective target. Alternatively, RNA aptamers are used to determine consensus sequences for the binding of the target in question. Alignments with genetic data reveal potential new target structures for already existing drugs. Utilization as antibodies in order to search for precursors of existing drugs which in turn can be screened for potential activity is another promising field of application.

\section{DNA aptamers for pharmaceuticals}

The following chapter reviews articles on DNA aptamers developed to detect pharmaceuticals. Since DNA aptamers are appropriate for various purposes in different research areas, examples described in this section include those aimed at medical, biotechnological, or environmental applications.

\section{DNA aptamers for antibiotics}

\section{Anthracyclines}

Anthracyclines are a class of antibiotics derived from Streptomyces bacteria and frequently used as cytostatics in chemotherapy to treat various kinds of cancers [62]. A high percentage $(\sim 37 \%)$ of these administrated anthracyclines is excreted unmetabolized in urine [63]. If not degraded or eliminated, they may accumulate in the environment and possibly reach the drinking water or contaminate the soil.

Wochner et al. [64] selected and characterized DNA aptamers with high affinity and specificity for the most common anthracyclines daunomycin and its hydroxyl derivate doxorubicin. The aptamer development was carried out by a semiautomatic in vitro selection [65] by using daunomycin as target, immobilized on magnetic beads. After ten rounds of selection, a group of daunomycinbinding aptamers with high-sequence similarity and a high G-content was identified and characterized. Competition of binding studies with fluorescent dye-linked aptamer assay [66], enzyme-linked aptamer assay (ELAA), and surface plasmon resonance assay (Biacore $\mathrm{X}$ ) determined the best binder and its specificity for daunomycin and doxorubicin. $K_{\mathrm{D}}$ values for daunomycin were $20 \mathrm{nM}$ for the best binder (clone 10.10) and $272 \mathrm{nM}$ for the 41-mer truncated sequence $10.10 \mathrm{v}$. The truncation experiments exposed the binding region as a G-rich domain with contiguous, stabilizing sequence parts.

\section{Tetracyclines}

Tetracyclines are a class of broad spectrum antimicrobial agents, which comprise various tetracycline nucleus derivates differing only in the presence or absence of $-\mathrm{H}$ and $-\mathrm{OH}$ groups around the tetracycline backbone. Tetracyclines are applied in human therapy, animal husbandry, aquafarming, and fruit crop production. They are extensively used in veterinary medicine and as growth promoters for animals. Only a small percentage of the administered antibiotics is metabolized in the animals. Accordingly, a large fraction is either accumulated in tissues or excreted. Hence, tetracyclines are found in food products like meat, milk, and eggs [67] or in the environment [68]. 
Niazi et al. [69, 70] selected ssDNA aptamers for tetracyclines by a combination of the Toggle-SELEX [71] and FluMag-SELEX [72] methods. Four rounds of FluMagSELEX with oxytetracycline immobilized on magnetic beads were accomplished before carrying out a counter SELEX with tetracycline. Each of the resulting fractions was subjected to a separate SELEX procedure. In one of these SELEX procedures [70], oxytetracycline beads were used, and after eight rounds of selection and a subsequent counter SELEX to doxycycline, five different types of sequences were found. Four of these bound specifically to oxytetracycline in a low nanomolar range $\left(K_{\mathrm{D}}=9.61 \pm 0.3 \mathrm{nM}\right.$ for aptamer no. $4,12.08 \pm 2.25 \mathrm{nM}$ for aptamer no. 5, 56.84 \pm $3.62 \mathrm{nM}$ for aptamer no. 20 , and $121.1 \pm 5.3 \mathrm{nM}$ for aptamer no. 2; performed by equilibrium dialysis). Aptamer no. 20 was highly specific for oxytetracycline with no or insignificant binding to tetracycline and doxycycline, followed by no. 5 and 4 . Aptamers no. 2 and 4 showed to possess a binding capacity of about $3-5 \%$ with tetracycline and doxycycline, but they also showed a considerably higher binding preference to oxytetracycline. The best binders were predicted to form G-quartet structures.

The other SELEX procedure [69] was carried out in two phases: In the first part, four SELEX rounds with oxytetracycline-modified beads were performed, with a tetracycline counterselection. In the following part of selection, tetracycline modified beads were used and a counterselection with doxycycline was done. After 12 SELEX rounds (all in all), 20 tetracycline group-specific aptamers were obtained which bound more than one analog of tetracycline antibiotics. Seven of these aptamers featured high affinities for the basic tetracycline backbone. Affinity constants of the aptamers were determined in the range of 63 to $483 \mathrm{nM}$ (values see Table 1). The palindromic sequence motif GGTGTGG or one of its truncated forms seems to be essential for binding to the tetracycline backbone, as one of them was present in all of the aptamers, including those binding to oxytetracycline.

\section{Kanamycins}

Kanamycins are a group of structural closely related aminoglycosidic antibiotics used to treat a broad variety of bacterial infections, especially in veterinary medicine. Despite their impressive clinical effectiveness, kanamycins are potentially ototoxic and nephrotoxic in humans and animals. Thus, monitoring the level of kanamycin residues in food or drinking water is essential for the maintenance of public health [73]. Commercially available kanamycin is a mixture of kanamycins $\mathrm{A}, \mathrm{B}$, and $\mathrm{C}$ but contains mainly kanamycin A $(\sim 75 \%)$. Another frequently used antibiotic of the kanamycin group is tobramycin.

Recently, DNA aptamers for kanamycin were selected by Song et al. [74]. The selection procedure was carried out by affinity chromatography, in which commercially available kanamycin was immobilized on cyanogen bromide-activated sepharose beads. After nine rounds of in vitro selection and amplification, six groups of aptamers with specificity for kanamycin and its derivatives were enriched. The binding aptamers had a high G-content, and the authors found a consensus region composed of a stem-loop with a double Gresidue in the loop that was shown to be necessary for binding. Binding assays with fluorescence-labeled oligonucleotides revealed affinity constants of $85.6 \mathrm{nM}$ for aptamer Kana2 as the aptamer with the strongest binding affinity to kanamycin out of the six selected aptamer groups. A minimized 21-mer from the Kana2 aptamer (called Ky2) containing the conserved secondary structure showed an affinity constant of $78.8 \mathrm{nM}$ for kanamycin. Ky2 also bound to both kanamycin B $\left(K_{\mathrm{D}}=84.5 \mathrm{nM}\right)$ and tobramycin $\left(K_{\mathrm{D}}=103 \mathrm{nM}\right)$. No binding could be detected to streptomycin, sulfadimethoxine, and ampicillin. The Ky2 aptamer has been applied in a gold nanoparticle-based colorimetric, simple, and easy-to-handle kanamycin assay, allowing detection of kanamycin at a level as low as $25 \mathrm{nM}$.

DNA aptamers for pharmaceuticals with psychotropic effects

\section{Cocaine}

Cocaine (benzoylmethylecgonine) is a crystalline tropane alkaloid and a derivative of ecgonine. Cocaine acts as a very strong stimulant of the central nervous system and as an appetite suppressant. It is a popular illegal drug with high addictive potential. Current studies pointed out the problematical contamination of cocaine in surface and waste waters in various countries [75-78].

Stojanovic et al. selected a cocaine-specific aptamer and were the first to describe its application [79-81]. The aptamer undergoes a formidable structure change while binding to cocaine. Because of this feature, a multitude of researchers applied this aptamer in various analytical systems [82-85]. However, there is no publication describing the actual aptamer selection. The cocaine aptamer called MNS-4.1 seems to provide the initial aptamer structure with the proposed cocaine binding pocket located in the center of a three-way junction structure [80]. The dissociation constant of this aptamer is given with $\sim 0.4$ to $10 \mu \mathrm{M}$ [80]. The aptamer MNS-7.9 was constructed by shortening one of the stems. It retained significant, albeit reduced affinity for cocaine with $K_{\mathrm{D}} \sim 20 \mu \mathrm{M}$ [80]. Moreover, the aptamer MNS4.1 was separated at a predicted loop into two subunits C2-D and F-C1 with $K_{\mathrm{D}} \sim 200 \mu \mathrm{M}$ [79]. Most of the multitude aptamer-based cocaine biosensors and assays are based on these aptamer structures. They are described in more detail in the "Aptamer-based detection systems" section. 
Table 1 Examples of aptamers selected for pharmaceuticals

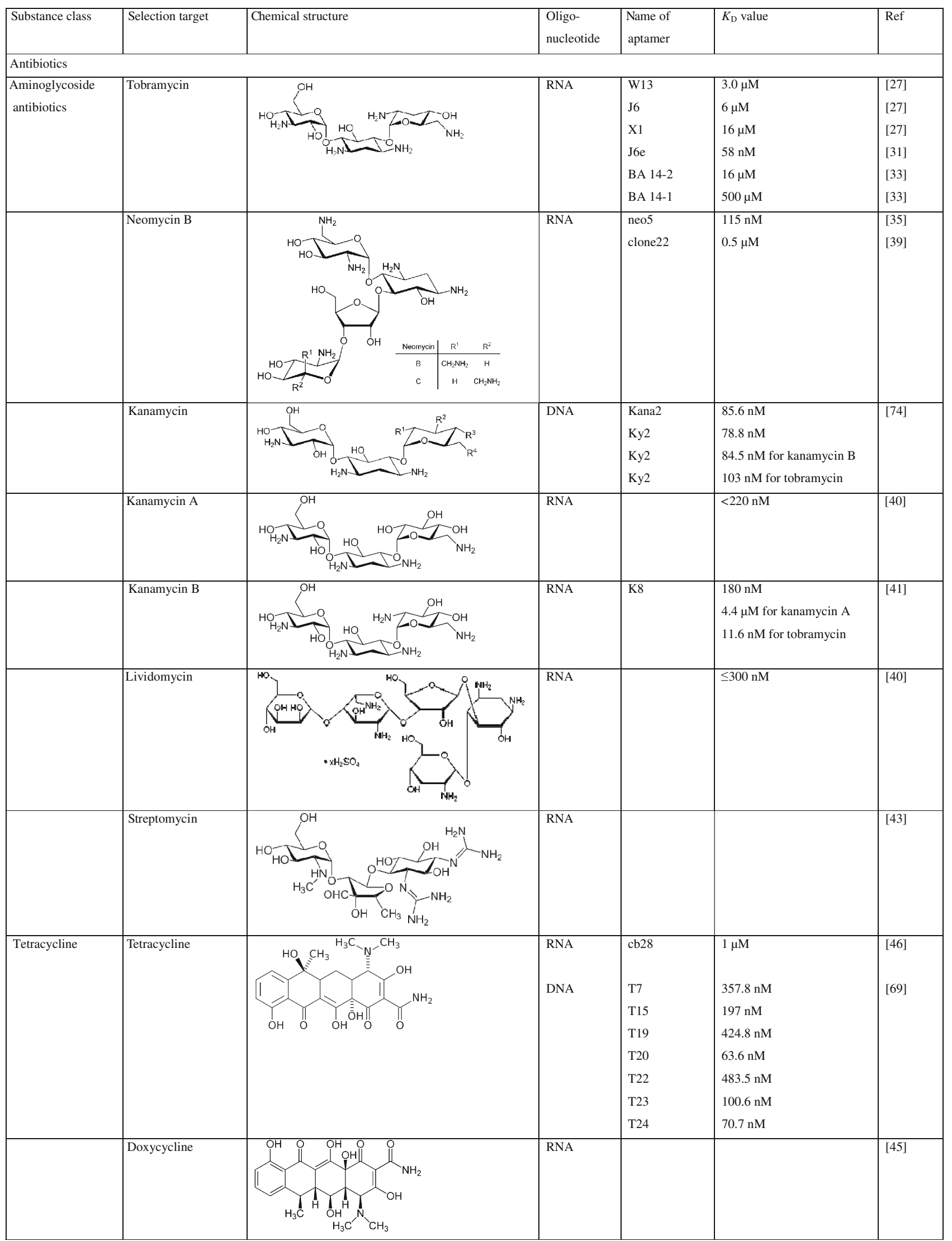


Table 1 (continued)

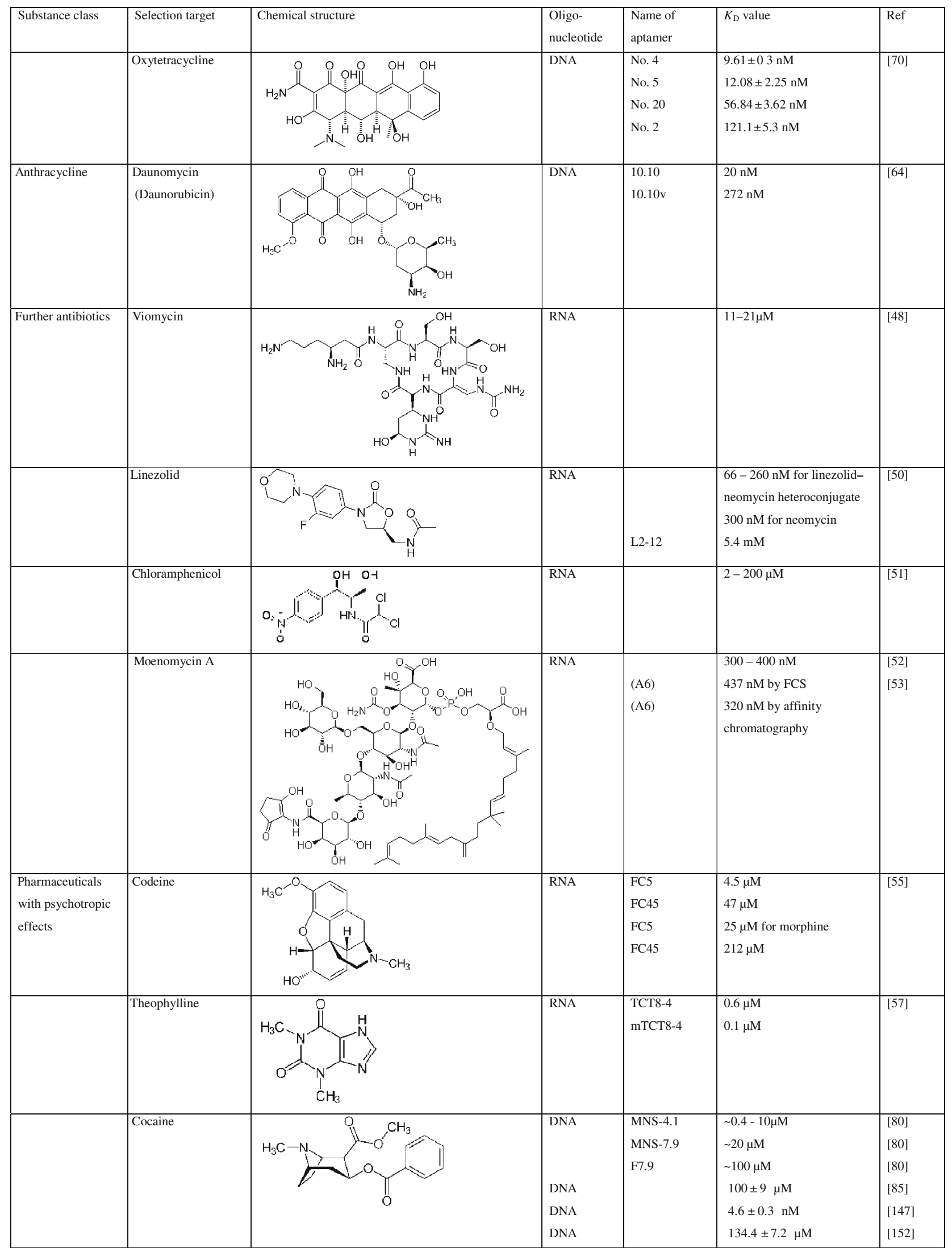


Table 1 (continued)

\begin{tabular}{|c|c|c|c|c|c|c|}
\hline Substance class & Selection target & Chemical structure & $\begin{array}{l}\text { Oligo- } \\
\text { nucleotide }\end{array}$ & $\begin{array}{l}\text { Name of } \\
\text { aptamer }\end{array}$ & $K_{\mathrm{D}}$ value & Ref \\
\hline & Thalidomide & & DNA & \begin{tabular}{|l|} 
T5-B \\
T5-1-B \\
T5-1a
\end{tabular} & $\begin{array}{l}113 \mu \mathrm{M} \\
133 \mu \mathrm{M} \\
1.05 \pm 0.59 \mu \mathrm{M}\end{array}$ & [89] \\
\hline & Dopamine & & RNA & \begin{tabular}{|l|} 
dopa2 \\
dopa $2 /$ c. 1
\end{tabular} & $\begin{array}{l}2.8 \mu \mathrm{M} \\
1.6 \mu \mathrm{M}\end{array}$ & [61] \\
\hline Analgetics & Diclofenac & & DNA & \begin{tabular}{|l} 
D10/DA24 \\
D22 \\
D16 \\
D3
\end{tabular} & $\begin{array}{l}100.64 \pm 40.5 \mathrm{nM} \\
166.34 \pm 57.9 \mathrm{nM} \\
148.73 \pm 15.5 \mathrm{nM} \\
42.7 \pm 15.9 \mathrm{nM}\end{array}$ & [94] \\
\hline & $\begin{array}{l}\text { Ibuprofen (racematic } \\
\text { form) }\end{array}$ & & DNA & \begin{tabular}{|l|} 
IBA2 \\
IBA8 \\
IBA12 \\
IBA4 \\
IBA17 \\
IBA4 \\
IBA17
\end{tabular} & $\begin{array}{l}3.0 \mu \mathrm{M} \text { (for racematic form) } \\
5.2 \mu \mathrm{M} \text { (for racematic form) } \\
3.2 \mu \mathrm{M} \text { (for racematic form) } \\
1.5 \mu \mathrm{M} \text { (for (S)-isomer) } \\
3.8 \mu \mathrm{M} \text { (for (S)-isomer) } \\
2.4 \mu \mathrm{M} \text { (for racematic form) } \\
6.8 \mu \mathrm{M} \text { (for racematic form) }\end{array}$ & [97] \\
\hline Hormones & Estradiol & & DNA & & $\begin{array}{l}0.1-3 \mu \mathrm{M} \\
0.13 \mu \mathrm{M}\end{array}$ & [102] \\
\hline & Somatropin & & DNA & & $218 \mathrm{nM}$ & [105] \\
\hline & Insulin & & $\overline{\text { DNA }}$ & & & {$[108]$} \\
\hline & Vasopressin & & DNA & $\begin{array}{l}\text { D-Aptamer } \\
\text { L-Aptamer }\end{array}$ & $\begin{array}{l}0.9 \mu \mathrm{M} \text { for } \mathrm{D} \text {-vasopressin } \\
1.2 \mu \mathrm{M} \text { for } \mathrm{L} \text {-vasopressin }\end{array}$ & [116] \\
\hline
\end{tabular}


Table 1 (continued)

\begin{tabular}{|c|c|c|c|c|c|c|}
\hline Substance class & Selection target & Chemical structure & $\begin{array}{l}\text { Oligo- } \\
\text { nucleotide }\end{array}$ & $\begin{array}{l}\text { Name of } \\
\text { aptamer }\end{array}$ & $K_{\mathrm{D}}$ value & Ref \\
\hline & Gonadoliberin & & $\begin{array}{l}\text { RNA } \\
\text { RNA } \\
\text { Spiegelmer } \\
\text { DNA } \\
\text { DNA } \\
\text { Spiegelmer }\end{array}$ & $\begin{array}{l}\text { A10 } \\
\text { A10 truncated } \\
\text { A10 truncated } \\
\text { Spiegelmer } \\
\text { S42 } \\
\text { S42 truncated } \\
\text { S42 truncated } \\
\text { Spiegelmer }\end{array}$ & $\begin{array}{l}92 \pm 12 \mathrm{nM} \text { for D-GnRH } \\
263 \mathrm{nM} \text { for D-GnRH } \\
190 \mathrm{nM} \text { for L-GnRH } \\
55 \pm 7 \mathrm{nM} \text { for D-GnRH } \\
45 \mathrm{nM} \text { for D-GnRH } \\
45 \mathrm{nM} \text { for L-GnRH }\end{array}$ & [122] \\
\hline
\end{tabular}

\section{Thalidomide}

Thalidomide (also known under the brand names Contergan ${ }^{\circledR}$ in Germany and Kevadon ${ }^{\circledR}$ in Canada and the USA) was introduced as a sedative drug in the late 1950s, but was withdrawn from the market in 1960 s due to its strong teratogenic and neuropathogenic effects. Thalidomide exists in two enantiomeric forms, the $(R)$ - and $(S)$-isomers which cause the differences in its biological activity. While the enantiomers can interconvert (racemize) in vivo [86], their pathogenic mechanisms are still not understood. Recently, thalidomide has been considered as a potential drug for various diseases such as autoimmune diseases, AIDS, Hansen's disease, and some cancers [87, 88].

Shoji et al. [89] generated a modified DNA aptamer that binds the $(R)$-isomer of a thalidomide derivate with high enantioselectivity. The aptamer selection was designed using the racematic thalidomide derivate, which was conjugated with biotin and immobilized on a streptavidin gel. A modified DNA library was applied which contained cationic ammonium groups attached by a hydrophobic hexamethylene linker at the thymidine residues $\left(\mathrm{T}^{\mathrm{HM}}\right)$. Fifteen rounds of selection were carried out, and the five aptamers with the highest binding affinities to thalidomide showed a high guanine content. Tests with the best binding aptamer exhibited that the modified group $\mathrm{T}^{\mathrm{HM}}$ was indispensable for the binding to thalidomide. An affinity constant of $113 \mu \mathrm{M}$ was determined for the selected aptamer T5-B (biotinylated) by SPR. The SPR measurements were carried out with a derivate of thalidomide which was conjugated with a PEG derivative as a weight tag. Truncated versions of the best binding aptamer T5 (T5-1, T5-2, and T5-3) were used to determine the thalidomide-binding site which was expected to form a stem-loop structure. The fragment T5-1 was suggested as the binding site of the aptamer T5. The dissociation constant for the aptamer fragment T5-1-B determined by SPR measurements was $133 \mu \mathrm{M}$ which is almost the same as that of the parent aptamer, T5-B. Studies with fluorescence titration revealed a high enantioselective binding behavior of the truncated aptamer T5-1a which recognized the $(R)$-isomer of thalidomide. The dissociation constant of T5-1a was estimated by fluorescence titration and was found to be $1.05 \pm 0.59 \mu \mathrm{M}$.

DNA aptamers for analgetics

\section{Diclofenac}

Diclofenac (DCF) is a nonsteroidal anti-inflammatory drug with analgetic, antiphlogistic, antipyretic, and antirheumatic properties. It is widely used to treat pain and inflammatory disorders including musculoskeletal complaints (arthritis, rheumatoid arthritis, polymyositis, dental pain, etc.). Diclofenac belongs to the most frequently detected pharmaceutically active compounds in the water cycle [90] causing critical side effects for humans and also harmful environmental impacts. Published are, e.g., noxious effects on vultures [91, 92] and on freshwater fish species [93].

Joeng et al. [94] produced DCF-binding aptamers by using the FluMag-SELEX process [72]. After nine selection rounds including counterselection steps with the structure analog 2-anilinophenylacetic acid (2APA) and 4-amino-3,5dichlorbenzoic acid, an enrichment of three major groups based on sequence similarity could be shown. Secondary structure analysis revealed typical stem-loop structures. The best binders D10/DA24, D16, D22, and D3 exhibited specificity to the selection target DCF. Aptamers D22 and D16 possessed higher specificities to 2APA than for DCF. 2APA is a structural analog of DCF lacking two chlorine 
atoms. For one of the aptamers (D3), specificity to DCF and no significant binding to 2APA could be shown. For all of these aptamers, no binding activity was detectable to 4amino-3,5-dichlorobenzoic acid (chemically not related) and to naked beads. The determined $K_{\mathrm{D}}$ values for immobilized diclofenac averaged between 42.7 and $166.34 \mathrm{nM}$ and are given in detail in Table 1.

\section{Ibuprofen}

Ibuprofen is another representative nonsteroidal antiinflammatory drug which offers analgetic, antiphlogistic, antipyretic, and antirheumatic properties. It is prevalently used for arthritis, primary dysmenorrhea, and fever. Due to the chirality of ibuprofen, there are two enantiomers with different physiological effects. The $(S)-(+)$-ibuprofen was found to be the active form both in vitro and in vivo [95], while $(R)-(-)$-ibuprofen seems to be teratogenic [96].

To generate an enantioselective DNA aptamer for ibuprofen, Kim et al. [97] carried out a FluMag-SELEX [72] process with racematic ibuprofen. Ten rounds of in vitro selection including counterselection steps with other nonsteroidal antiinflammatory drugs (fenoprofen, flubiprofen, naproxen) were performed. After this procedure, five different sequences (mostly G-rich) could be found. They could be divided into two sequence groups depending on the found consensus regions. The aptamers of the first group (IBA2, IBA8, IBA12) showed binding affinity to the racemic mixture of ibuprofen but were not able to bind pure $(S)$-ibuprofen. On this account, the authors concluded that they are specific for the $(R)$-isomer. The affinity constants for this sequence group were determined by an affinity elution assay to be $3.0 \mu \mathrm{M}$ (IBA2), $5.2 \mu \mathrm{M}$ (IBA8), and $3.2 \mu \mathrm{M}$ (IBA12). The aptamers of the second group (IBA4, IBA17) possessed binding affinities to the $(S)$-isomer $\left(K_{\mathrm{D}}=1.5 \mu \mathrm{M}\right.$ (IBA4) and $3.8 \mu \mathrm{M}$ (IBA17)) as well as to the racematic form $\left(K_{\mathrm{D}}=2.4 \mu \mathrm{M}\right.$ (IBA4) and $6.8 \mu \mathrm{M}$ (IBA17)) of ibuprofen. Neither the first sequence group nor the second showed any binding affinity to the other tested nonsteroidal anti-inflammatory drugs fenoprofen, flubiprofen, and naproxen or to oxytetracycline.

DNA aptamers for hormones

\section{Estradiol}

Estradiol (also $17 \beta$-estradiol or E2) is one of the predominant sex hormones belonging to the class of steroid hormones. Derivatives of estradiol are the most common estrogen ingredients in combined oral contraceptive pills. Estradiol itself has been widely applied in animal fattening for its anabolic effects [98]. It is well-known that endocrinedisrupting chemicals, including estradiol, have harmful effects on aquatic organisms (e.g. [99, 100]). Also humans are affected by chronic exposure since these chemicals reach the natural aquatic systems and the drinking water [101].

Kim et al. [102] obtained $17 \beta$-estradiol-specific ssDNA aptamers after seven cycles of selection and enzymatic enrichment in a SELEX process. The aptamers were analyzed concerning their affinity to estradiol. Based on the equilibrium filtration method, affinity constants for the ten obtained aptamers were determined to be in a range of 0.1 to $3 \mu \mathrm{M}$, with a $K_{\mathrm{D}}=0.13 \mu \mathrm{M}$ for the best binding oligonucleotide. Secondary structure analysis indicated a stem-loop structure for this estradiol aptamer. The aptamer was used in an electrochemical detection method by immobilizing the aptamer on a gold electrode chip. In that way, the authors could show that the aptamer had no cross-reactivity to small organic chemicals with structural similarities to estradiol (methoxynaphthalene, aminoanthraquinone).

Huy et al. [103] used this aptamer for a novel separation and enrichment method of $17 \beta$-estradiol from aquatic samples by application of aptamer-anchored microbeads. To achieve this, the estradiol-specific aptamers were aminotagged and covalently attached to isothiocyanate modified glass beads. The experiments revealed a specific binding and enrichment of $17 \beta$-estradiol from spiked water samples. No binding to the antibiotics chloramphenicol and 3-[[(4carboxyphenyl) methylene] amino]-2-oxazolidinone and a weak cross-reactivity to the estrogen diethylstilbestrol was detected. The results of this study demonstrate the ability of aptamer-based affinity methods for the separation and enrichment of chemicals from environmental water samples.

\section{Somatropin}

Somatropin is the recombinant produced human growth hormone (rhGH). In contrast, the natural human growth hormone (hGH) is called somatotropin. Both are anionic, nonglycosylated four helix-bundle proteins. Somatropin has a strong anabolic effect. Therefore, it is often misused by athletes to enhance their performance. But it is also applied as medication to treat hypopituitary dwarfism, injuries, bone fractures, bleeding ulcers, and burns [104].

Calik et al. [105] selected aptamers for somatropin using the so-called single-step ligand evolution by temperature gradient method. The characteristic step of this method is an elution of the target-bound oligonucleotides by a temperature gradient. In this way, the authors assumed that aptamers with higher specificity to the target are separated from those aptamers with lower specificity. At first, a negative selection step with extracellular proteins of Bacillus subtilis was performed because the aim of the aptamer development was to separate and purify rhGH (somatropin) during the production process from $B$. subtilis fermentation broth. After this pre-selective step, the obtained oligonucleotide pool was incubated with somatropin microparticles. The somatropin- 
binding oligonucleotides were eluted stepwise by a temperature gradient within a range of $T=55{ }^{\circ} \mathrm{C}$ to $95{ }^{\circ} \mathrm{C}$. At a temperature of $85{ }^{\circ} \mathrm{C}$, eight aptamer sequences with high affinity to somatropin were eluted. The $K_{\mathrm{D}}$ value of the best binder was determined to be $218 \mathrm{nM}$ by equilibrium binding analysis. By utilization of this aptamer immobilized on microparticles, the authors were able to separate and purify rhGH (somatropin) from the B. subtilis fermentation broth with a purity of $99.8 \%$.

Bruno et al. [106] developed aptamers, which are able to discriminate between somatropin $(\mathrm{rhGH})$ and somatotropin (hGH) and bind these hormones in different levels. The aptamers were obtained after five rounds of a microbeadbased SELEX procedure with rhGH and hGH as targets. Eight of the found aptamer sequences indicated the ability to discriminate recombinant produced somatropin ( $\mathrm{rhGH}$ ) from natural somatotropin (hGH). Sequence analyses discovered GGGTG as the most common sequence segment. Specificity tests by enzyme-linked aptamer assay were carried out to determine cross-reactivity to proteins or peptides of human body fluids and others. Regrettably, the best rhGH discriminatory aptamers exhibited a crossreactivity to human myoglobin and to BSA (but not to bone collagen peptides and to an unrelated viral envelope peptide), which makes them inappropriate for measurements of rhGH/ hGH in body fluids.

\section{Insulin}

The well-known peptide hormone insulin has central functions in carbohydrate and fat metabolism in vertebrates. Dysfunctions in insulin balance lead to Diabetes mellitus and related metabolic disorders. Worldwide, millions of patients with diabetes depend on external insulin for their survival because the hormone is no longer produced internally. For this widespread clinical use, biosynthetic "human" insulin is manufactured recombinantly [107].

To select insulin-binding aptamers, Yoshida et al. [108] applied an ssDNA library which was expected to form various kinds of G-quartet structures. This approach was chosen because an insulin-linked polymorphic region (ILPR) in the human insulin gene promoter was found that can form an intramolecular G-quartet structure [109, 110]. The in vitro selection itself was carried out by aptamer blotting. In order to do this, human insulin as the target was immobilized on a modified polyethersulfone affinity membrane. By using this method, the binding of the oligonucleotides to the target protein could be visualized. After six rounds of selection, three aptamer sequences were obtained. Investigations of the binding ability to insulin in solution by fluorescence polarization measurement exhibited that two of the aptamers had a higher affinity to insulin than ILPR (which can be called "natural insulin-binding aptamer"). Circular dichroism spectrum measurements revealed the aptamer folding into a G-quartet structure while binding to insulin. Complementary, the authors developed an aptameric enzyme subunit (AES) by connecting the selected insulin-binding aptamer with a thrombin-inhibiting aptamer [111] for insulin detection. Using this AES, it was possible to detect insulin by measuring enzymatic activity of thrombin.

\section{Vasopressin}

Vasopressin (also arginine vasopressin or antidiuretic hormone) is a potent endogenous peptide hormone that controls the re-absorption of molecules in the tubules of the kidneys by affecting the tissue's permeability. It also increases peripheral vascular resistance, which in turn increases arterial blood pressure. It plays a key role in homeostasis and the regulation of water, glucose, and salts in the blood. It acts as a neurotransmitter in the brain to control the circadian rhythm, thermoregulation, and adrenocorticotropic hormone release [112-114]. The therapeutic use of vasopressin has become increasingly important in intensive care, in the management of cranial diabetes insipidus, bleeding abnormalities, esophageal variceal hemorrhage, asystolic cardiac arrest, and septic shock [115].

Williams et al. [116] generated a mirror-image ssDNA aptamer (L-DNA aptamer, similar to Spiegelmers [117]) to achieve a nuclease-insensitive ligand. The aptamer selection was carried out using the "selection-reflection" strategy. First step of this procedure is the production of an enantiomer (D-isomer) of the cyclic L-peptide arginine vasopressin. This D-isomer of vasopressin was used as target for the selection of natural D-ssDNA aptamers. The SELEX process was realized by affinity chromatography [118]. The implemented oligonucleotide library was produced with a raised G-content because the authors expected G-quartet structures for binding. Consequently, it was not surprising that the received vasopressin aptamers exhibited a high G-content. The binding region could be defined as a stem with an internal loop of 20 nt that contains guanine nucleotides at conserved positions. The truncated version of the D-ssDNA aptamer, containing only the binding region, was mirror-imaged into its L-form and tested for its ability to bind natural L-vasopressin. This L-aptamer exhibited a more than 100 -fold preference for vasopressin compared to oxytocin which is the closest known human analog (differing only in two peptide residues). Dissociation constants were ascertained by equilibrium dialysis experiments and were determined to be $0.9 \mu \mathrm{M}$ for D-aptamer/D-vasopressin and $1.2 \mu \mathrm{M}$ for $\mathrm{L}$-aptamer/Lvasopressin. Stability and nuclease insensitivity of the D-/Laptamer was proofed with the following results: The Laptamer stayed unaffected within 10 days, and the D-aptamer was degraded after $10 \mathrm{~s}$ by purified nucleases. Furthermore, the L-aptamer was not degraded in human serum and only to 
a small extent in calf serum. Additionally, the bioactivity of the L-aptamer as a vasopressin antagonist was confirmed in cell culture.

\section{Gonadoliberin}

Gonadoliberin is a peptide hormone (also gonadotropinreleasing hormone I (GnRH) or gonadorelin) responsible for the release of follicle-stimulating hormone and luteinizing hormone [119]. Therapeutically, it is often used in cases of fertility dysfunctions [120]. Gonadoliberin analogs are applied to treat breast or prostate carcinoma, endometriosis, and precocious puberty [121].

Leva et al. [122] assembled GnRH-specific RNA and DNA Spiegelmers. Initially, a SELEX process to get natural D-RNA and D-ssDNA ligands for mirror-imaged gonadoliberin (DGnRH) was implemented. In both cases, the selection for RNA and DNA aptamers was carried out by affinity chromatography using D-GnRH immobilized on thiol-modified sepharose. After six rounds of the RNA-SELEX, only one major binding sequence (named A10) was found which bound D-GnRH with a $K_{\mathrm{D}}$ value of $92 \pm 12 \mathrm{nM}$ (determined by equilibrium dialysis). Eight rounds of the DNA-SELEX led to nine different sequences which were able to bind GnRH. A $K_{\mathrm{D}}$ value of $55 \pm 7 \mathrm{nM}$ could be determined for the DNA aptamer with the highest affinity (named S42). The selected RNA and DNA variants showed no similarity to each other, neither concerning their primary sequence nor their proposed secondary structure. Truncations to ascertain the minimal binding domain indicated that $48 \mathrm{nt}$ of the RNA aptamer form a three-way helix junction with four unpaired nucleotides at the branching point, while the DNA aptamer (68 nt) forms a G-quadruplex structure flanked by two stems. Further substitutions and deletions led to a 60-nt DNA aptamer which bound to D-GnRH with $K_{\mathrm{D}}=45 \mathrm{nM}$. The affinity constant of the Spiegelmer to L-GnRH was the same. Both constants were determined by equilibrium dialysis. The affinity constants for the truncated RNA aptamer and its Spiegelmer were determined by isothermal calorimetry. The 50-nt truncation of the RNA aptamer A10 showed $K_{\mathrm{D}}=$ $263 \mathrm{nM}$ to D-GnRH, whereas the Spiegelmer L-RNA bound to L-GnRH with $K_{\mathrm{D}}=190 \mathrm{nM}$. Truncation of the RNA aptamer to a 50-mer decreased the binding affinity to half, whereas truncation of the best binding DNA sequence to a 60-mer did not alter the binding affinity [122].

Specificity tests were carried out by SPR real-time kinetic measurements. Both Spiegelmers exposed high specificity for gonadoliberin since the exchange of a single amino acid resulted in a dramatic loss of binding affinity (shown for chicken LHRH). The RNA Spiegelmer also recognized the $\mathrm{GnRH}$ analog buserelin, albeit with reduced affinity, while the DNA Spiegelmer showed nearly no binding to buserelin. No binding activity could be detected to the completely unrelated peptides vasopressin and oxytocin. Cell experi- ments clearly demonstrated that both Spiegelmers were able to inhibit the binding of GnRH to its cell surface receptor.

In contrast to the development of RNA aptamers, DNA aptamers for pharmaceuticals are often selected for diagnostic and analytical applications. DNA aptamers are therefore widely used to analyze body fluids. However, they are equally valuable for the detection of pharmaceutical residues in food or in the environment. Moreover, some research groups develop protocols not to implement aptamers in measurement and detection systems, but for application as affinity components in enrichment and purification methods. In contrast to DNA aptamers, the development of Spiegelmers is generally focused on a therapeutic application.

Independent of both the designated application and the selection method, it is remarkable that most DNA aptamers developed for pharmaceuticals exhibit a high guanine content. In several cases, G-quadruplex structures were identified as the binding regions, and it is noteworthy that also the "natural" aptamer for insulin (the insulin-linked polymorphic region in the human insulin gene promoter) forms an intramolecular G-quartet structure [109, 110]. Several studies indicate these structures to form highly competent binding configurations, especially for small bioactive molecules [123-125]. Considering the innumerable possibilities for the potential formation of G-quadruplex structures on the genomic level, these structures may occur more often in living cells than currently anticipated. Besides that, G-quadruplexes seem to be very convenient ligands for small molecules with pharmaceutical properties.

\section{Aptamer-based detection systems}

In comparison to other biological recognition elements, such as antibodies, aptamers are more stable to biodegradation and less vulnerable to denaturation. Their target binding is regenerative. Therefore, they are prime candidates for biosensors and assays in a number of applications, such as environmental monitoring and medical diagnostics [126]. The key challenge to their successful application is the transformation of the aptamer-binding events into physically detectable signals. To meet the challenge, a number of methods have been developed. Some aptamers bind their target by a contemporaneous structure switch. Such biomolecular switches enable transduction of the binding event into a specific output signal in a single step and without the addition of exogenous reagents and without the use of labels [127]. They can be used also in connection with markers (labels) fixed to the structure. These markers can be for instance redox active or optically active. The binding between the structure switching aptamer and its target induces a change of steric configuration of the aptamer 
causing a change in the measuring signal. Aptamer modification with electrochemically or optically active labels is very easy because the chemical synthesis procedures used for aptamer production provide a lot of standard methods for chemical binding of reporter molecules or reactive groups.

Most of the aptamer-based detection systems are described with one of the well-known aptamers for thrombin or cocaine serving as model aptamers. Cocaine belongs to the psychotropic pharmaceuticals, and therefore, these aptamer-based sensors are included in this review.

Biosensors couple the biological recognition of the analyte by a biological receptor (which may be an aptamer- "aptasensor" [128]) with a chemical or physical transducer. The characteristic feature of the biosensor is, according to the International Union of Pure and Applied Chemistry definition, the direct contact of the recognition element and the transducer [129]. The aptamer-based systems for the detection of pharmaceuticals reviewed in this article include not only biosensors which fulfill this definition but also optical assays with separated aptamerbased detection and signal recognition, for instance in colorimetric assays or test strips. The sections below give detailed descriptions about the aptamer-based sensors and assays, summarized at a glance in Table 2.

\section{Electrochemical aptasensors}

Electrochemical transducers offer some advantages in comparison to optical and other transducers such as ultrahigh sensitivity and simplicity [130]. Electrochemical transducers are the most frequently used in commercialized biosensors, for instance for blood glucose testing. The small size of

Table 2 Examples of aptamer-based biosensors and assays for pharmaceutical detection

\begin{tabular}{|c|c|c|c|c|c|c|}
\hline $\begin{array}{l}\text { Target/ } \\
\text { measurement of }\end{array}$ & $\begin{array}{l}\text { DNA/RNA } \\
\text { aptamer }\end{array}$ & $\begin{array}{l}\text { Ref of aptamer } \\
\text { description }\end{array}$ & Transducer/assay & Limit of detection & Linear range $(\mu \mathrm{M})$ & $\begin{array}{l}\text { Ref of } \\
\text { sensor/assay }\end{array}$ \\
\hline Oxytetracycline & DNA & {$[70]$} & ec, chip system, labeled & & $0.005-0.1$ & [137] \\
\hline Tetracycline & DNA & [69] & $\begin{array}{l}\text { ec, screen-printed electrode, } \\
\text { CV, SWV, label-free }\end{array}$ & $10 \mathrm{nM}$ & $0.01-10$ & [139] \\
\hline Neomycin & RNA & {$[35]$} & $\begin{array}{l}\text { ec, competitive impedimetric, } \\
\text { label-free }\end{array}$ & & $0.75-500$ & {$[140]$} \\
\hline Tobramycin & RNA & {$[27]$} & $\begin{array}{l}\text { ec, competitive impedimetric, } \\
\text { label-free }\end{array}$ & $\begin{array}{l}\text { ATA } 0.7 \mu \mathrm{M} \\
\text { FATA } 0.4 \mu \mathrm{M}\end{array}$ & $\begin{array}{l}\text { ATA } 1.4-70 \\
\text { FATA } 0.8-34.9\end{array}$ & [141] \\
\hline Aminoglycoside & RNA & {$[27]$} & ec, labeled & & $2-6$ & [142] \\
\hline Cocaine & DNA & {$[80]$} & Optical, colorimetric, labeled & & $50-500$ & [126] \\
\hline Cocaine & DNA & {$[80]$} & Optical, FRET, labeled & & $\begin{array}{l}10-4,000 \text { in blood } \\
\text { serum }\end{array}$ & {$[80]$} \\
\hline Cocaine & DNA & {$[80]$} & Optical, colorimetric dipstick & $10 \mu \mathrm{M}$ & & [149] \\
\hline Cocaine & DNA & {$[80]$} & ec, microfluidic, labeled & & $\begin{array}{l}10-100 \text { in blood } \\
\text { serum }\end{array}$ & {$[85]$} \\
\hline Cocaine & DNA & {$[80]$} & Optical, FRET, labeled & $10 \mu \mathrm{M}$ & $10-1,000$ & This publication \\
\hline Cocaine & DNA & {$[79]$} & Optical, FRET, labeled & & $10-1,250$ & {$[79]$} \\
\hline Cocaine & DNA & [79] & $\begin{array}{l}\text { Optical, FRET, labeled } \\
\text { Optical, excimer fluorescence, } \\
\text { labeled } \\
\text { ec, LSV, labeled }\end{array}$ & $\begin{array}{l}1 \mu \mathrm{M} \\
100 \mu \mathrm{M} \\
10 \mu \mathrm{M}\end{array}$ & $\begin{array}{l}1-1,000 \\
100-1,000 \\
10-1,000\end{array}$ & [143] \\
\hline Cocaine & DNA & {$[80]$} & ec, CV, labeled & $<10 \mu \mathrm{M}$ & & {$[82]$} \\
\hline Cocaine & DNA & {$[79]$} & ec, pulse voltammetry, label-free & $0.1 \mu \mathrm{M}$ & $0.1-38.3$ & [145] \\
\hline Cocaine & DNA & [79] & ec, chronocoulometric, label-free & $70 \mathrm{nM}$ & $0.1-26.3$ & {$[130]$} \\
\hline Cocaine & DNA & {$[80]$} & Optical, colorimetric, labeled & $50 \mathrm{nM}$ & $0.1-20$ & [153] \\
\hline Cocaine & DNA & {$[80]$} & $\begin{array}{l}\text { Electrogenerated chemiluminescence, } \\
\text { labeled }\end{array}$ & $1 \mathrm{nM}$ & $0.005-0.3$ & [146] \\
\hline Cocaine & DNA & {$[80]$} & $\begin{array}{l}\text { Optical, fluorescence, rolling } \\
\text { circle amplification, labeled }\end{array}$ & $0.48 \mathrm{nM}$ & $0.001-0.05$ & {$[154]$} \\
\hline Cocaine & DNA & {$[82]$} & $\begin{array}{l}\text { Electrogenerated chemiluminescence, } \\
\text { labeled }\end{array}$ & $10 \mathrm{pM}$ & & {$[147]$} \\
\hline Vasopressin & L-DNA & [116] & Optical, SERS, label-free & $5.2 \mu \mathrm{U} / \mathrm{ml}$ & & {$[155]$} \\
\hline Dopamine & RNA & {$[61]$} & $\begin{array}{l}\text { Optical, colorimetric, ELAA, } \\
\text { labeled }\end{array}$ & $1 \mathrm{pM}$ & $0.00005-0.1$ & {$[156]$} \\
\hline $17 \beta$-Estradiol & DNA & {$[102]$} & ec, CV, SWV, label-free & & $0.00001-0.001$ & [102] \\
\hline
\end{tabular}

$C V$ cyclic voltammetry, ec electrochemical, ELAA enzyme-linked aptamer-based assay, FRET fluorescence resonance energy transfer, $L S V$ linear sweep voltammetry, SERS surface-enhanced Raman spectroscopy, $S W V$ square wave voltammetry 
electrodes and the possibility to miniaturize the detection unit as sensor or chip system and to integrate them with the electronics of the device permit the construction of hand-held devices or in-field/at-side devices. Aptamer-based biosensors with electrochemical transduction [131-133] and also with various amplification methods of the aptamer-based signaltracing are described [130].

Sassolas et al. have reviewed articles about electrochemical aptasensor development written in the years between 2004 and 2009 [134]. The article presents clearly drawn schemes of the different configurations of labeled and non-labeled detection and between signal-on and signal-off electrochemical detection principles and describes advantages and disadvantages of them.

Sadik et al. describe in their review dealing with biomolecular recognition by use of electrochemical techniques various electrochemical aptasensors that were developed recently [135]. Electrochemical detection of the aptamer reaction with the target is based on labels such as enzymes, nanoparticles, quantum dots, or redox active molecules, or on a binding-induced label-free detection. A reagentless, electrochemical aptamer-based sensor (E-AB sensor) was developed $[82,133,136]$, which is a platform for aptamerbased detection. One of the ends of the aptamer is immobilized at the electrode surface. At the other end, a redox active label is attached to the aptamer, which is able to undergo a redox reaction with the electrode. In the case of binding of the target molecule to the aptamer, its conformation is changed and the distance between the redox active label and the electrode surface is decreased, which in turn causes a change in the electrochemical signal. Even though-regarding pharmaceuticals - aptamers were developed for many substances and substance classes, only a few of them are in fact used in electrochemical biosensors. In the sections below, electrochemical aptasensors for antibiotics, psychotropics, and hormones are described as they are found in the literature.

\section{Antibiotics}

An electrochemical aptamer-based chip system, consisting of a gold working electrode chip with eight electrodes in parallel and using the $\mathrm{K}_{3} \mathrm{Fe}(\mathrm{CN})_{6}$ redox mediator (comparable to the system described in [102]) was used for oxytetracycline detection. Kim et al. immobilized the thiol-modified oxytetracycline specific DNA aptamer no. 14 described in [70] on a gold interdigitated array [137]. The reference and counter electrode used are not specified in their work. The redox reaction between ferrocyanide and ferricyanide is measured by cyclic voltammetry (CV) and square wave voltammetry (SWV) before and after binding of oxytetracycline to the immobilized aptamers. The dynamic range of the sensor lies between 5 and $100 \mathrm{nM}$ oxytetracycline. Structurally related tetracycline derivatives such as doxycycline and tetracycline were distinguished from oxytetracycline [137]. Sensor regeneration was achieved by use of $2 \mathrm{M} \mathrm{NaCl}$ [137, 138].

Kim et al. [139] used a screen-printed gold electrode with silver reference electrode and gold counter electrode for the immobilization of the tetracycline binding DNA aptamer T20, whose selection was described in [69]. The aptamer was extended by a poly- $T$ tail for flexibility and spacing at the $5^{\prime}$-end and labeled with biotin to immobilize it at the streptavidin-modified electrode. The same detection principle as in the sensor example above was used: The redox reaction of the redox mediator $\mathrm{K}_{3} \mathrm{Fe}(\mathrm{CN})_{6}$ was measured by $\mathrm{CV}$ and $\mathrm{SWV}$ at the aptamer-modified electrode before and after binding of the target. The decrease of the current quantifies the target bound to the aptamer. This label-free sensor showed a dynamic range for tetracycline detection of $10 \mathrm{nM}$ to $10 \mu \mathrm{M}$ and a limit of detection of $10 \mathrm{nM}$ tetracycline. The aptamer used in this aptasensor can weakly recognize other tetracyclines like oxytetracycline and doxycycline [69], so the sensor has lower specificity and can detect tetracycline and its derivatives [139].

Faradaic impedance spectroscopy was used for neomycin detection with a competitive RNA aptamer sensor [140]. The neomycin B-specific RNA aptamer [35, 37] was stabilized by 2 '-O-methylation. The aptamer was bound to neomycin $\mathrm{B}$ immobilized on a gold electrode. The assay procedure consists of 5-min incubation of the electrode in the affinity solution with varying concentrations of neomycin B and subsequent transformation to the measuring solution, which contains the redox probe $\left[\mathrm{Fe}(\mathrm{CN})_{6}\right]^{3-/ 4-}$. The impedance spectrum at a bias potential of $+0.225 \mathrm{~V}\left(\mathrm{Ag} / \mathrm{AgCl} / \mathrm{KCl}_{\mathrm{sat}}\right)$ using a frequency range from $10 \mathrm{kHz}$ to $100 \mathrm{mHz}$ and an alternating current amplitude of $5 \mathrm{mV}$ is measured. The increase of neomycin B in the affinity solution causes an increasing aptamer displacement from the electrode which is measured as an impedance change [140]. The linear range of the label-free sensor is from 0.75 to $500 \mu \mathrm{M}$ neomycin B. The measurement is fast because the aptamer displacement by neomycin B requires only $5 \mathrm{~min}$. The electrode surface can be regenerated. In concentrated neomycin solution, all remaining aptamers are released. Further rebinding of the aptamer results in a fresh aptamer-bound surface [140]. The sensor was stored in neomycin solution. One week storage and 20 measurement cycles are possible without significant loss in sensitivity. The practical test was done in milk spiked with neomycin. The sample pretreatment consisted in 1:5 dilution of the sample in affinity buffer and ultracentrifugation. The linear range for the measurement in milk is between $25 \mu \mathrm{M}$ and $2.5 \mathrm{mM}$ neomycin B [140].

A comparable RNA aptamer-based displacement impedimetric sensor for tobramycin detection was described by Gonzalez-Fernandez et al. [141]. The RNA aptamer developed by Wang and Rando [27] was stabilized by $2^{\prime}-O$-methylation 
in the same way as the neomycin RNA aptamer mentioned before and described in [140]. Two types of aptamer methylation were tested, the fully modified aptamer (FATA) is methylated at each base, in contrast to the partially modified aptamer called ATA. The aim of this study was to detect tobramycin in human serum. Both aptamers were tested in the displacement assay by use of the impedimetric sensor which worked as described before for neomycin detection [140]. The changes in the electron transfer resistance that resulted from biosensing events between the redox probe $\left(\left[\mathrm{Fe}(\mathrm{CN})_{6}\right]^{3-/ 4-}\right.$ ) and the modified electrode were measured as the impedance spectra (at a bias potential of $+0.225 \mathrm{~V}\left(\mathrm{Ag} / \mathrm{AgCl} / \mathrm{KCl}_{\text {sat }}\right)$ using a frequency range from $10 \mathrm{kHz}$ to $100 \mathrm{mHz}$ and an alternating current amplitude of $5 \mathrm{mV}$ ). In this way, the analyte tobramycin could be detected in solution by the displacement of aptamers bound to the tobramycin-modified sensor surface. The ATA aptamer showed a limit of detection of $0.7 \mu \mathrm{M}$ and a linear range of 1.4 to $70 \mu \mathrm{M}$ for tobramycin. Regeneration of the sensor surface was done by incubation in concentrated tobramycin solution for $1 \mathrm{~h}$, removing all of the aptamer molecules from the electrode surface. Subsequently, the tobramycin-modified surface can be re-saturated by the aptamer and re-used for measurement. The sensor could be used for 1 week when stored between measurements in the regeneration solution (conc. tobramycin solution) at $4{ }^{\circ} \mathrm{C}$. The selectivity was tested with respect to the aminoglycosides kanamycin, neomycin B, paromomycin, and streptomycin. The tobramycin-ATA aptamer sensor was able to discriminate between tobramycin and kanamycin, paromomycin, and streptomycin. However, neomycin B could be detected by the sensor producing signals nearly the same as tobramycin. By use of the fully methylated aptamer (FATA), a limit of detection of $0.4 \mu \mathrm{M}$ and a linear range of 0.8 to $34.9 \mu \mathrm{M}$ were found, which were in good agreement with the results of ATA aptamer, suggesting similar affinities for both aptamers for its target tobramycin. The measurement of tobramycin in human serum was possible in the therapeutic concentration range [141].

An RNA aptamer-based E-AB sensor for aminoglycoside antibiotics detection is able to detect tobramycin, kanamycin, and gentamicin. This aptamer does not discriminate between these three aminoglycosides binding all three with similar affinities. This sensor was developed for point-of-care diagnostics. It allows measurement of aminoglycoside concentrations over the therapeutically relevant low micromolar range (2 to $6 \mu \mathrm{M}$ ). Methylene blue (MB) is used as the redox tag at the 3'-end of the RNA aptamer. The binding of the aminoglycosides to the electrode-bound aptamer causes a decrease in Faradaic current from the attached redox tag. Nucleases in serum samples are removed by ultrafiltration, which is possible for the detection of the small aminoglycoside molecules. The measurement process with sample pretreatment is complete in less than $30 \mathrm{~min}$ [142].
Pharmaceuticals with psychotropic effects

A rapid electrochemical aptamer biosensor for cocaine detection is based on the target-induced conformational change of the aptamer [82]. Baker et al. used the cocaine DNA aptamer F7.9D described by Stojanovic et al. [80] and coupled a MB redox tag to it. These modified aptamers were immobilized on a gold electrode by self-assembly via an alkanethiol group. The methylene blue reduction peak of the $\mathrm{AC}$ voltammogram increases with increasing cocaine concentration. The authors assume that in the absence of the target cocaine the aptamer remains partially unfolded, but with addition of cocaine the aptamer folds into a typical three-way junction structure causing an alteration of the MB reduction peak. The sensor is "signal on," in contrast to the decreasing signal for the thrombin sensor described one year before [131]. The thrombin sensor construction was the same, whereas the thrombin aptamer shows a different folding reaction on target binding. The thrombin DNA aptamer folds into a G-quadruplex structure in the presence of the target [131] in contrast to the cocaine aptamer which folds into a three-way junction structure [82]. In the first case the signal changes are caused by the MB tag, which veers away from the sensor surface, and in the second case the MB tag approaches the electrode surface. The detection limit of the cocaine biosensor is given to be below $10 \mu \mathrm{M}$. The sensor enables an easy detection of $500 \mu \mathrm{M}$ cocaine in fetal calf serum or human saliva [82].

A microfluidic electrochemical aptamer-based sensor (MECAS) was developed [85] based on the same cocaine aptamer F7.9D [80] which was labeled with $\mathrm{MB}$ for electrochemical sensing of the target binding as described directly before [82]. The MECAS chip consists of three gold electrodes at which the thiolated aptamer is immobilized, a platinum counter electrode and a platinum reference electrode within a 750-nl detection chamber. By use of this microfabricated electrochemical aptamer biosensor, the continuous, real-time detection of cocaine in undiluted, unmodified blood serum in the physiological range was shown [85]; 10 to $100 \mu \mathrm{M}$ cocaine in blood serum was measured, and the dissociation constant for the aptamer binding was determined to be $100 \pm 9 \mu \mathrm{M}$, which is identical to that for the aptamer in solution $[80,85]$.

Another MECAS is reported by $\mathrm{Du}$ et al. [130] for simultaneous detection of ATP and cocaine as model targets. Here we will only review the cocaine detection by this method, because ATP is not a relevant pharmaceutical residue which has to be detected by environmental monitoring. Two cocaine aptamer fragments derived from [79] were used. This MECAS chip consists of four groups of threeelectrode systems. Each group of three-electrode systems consisted of two gold working electrodes, which shared one gold counter electrode and one Ag reference electrode. 
Polydimethylsiloxane-based microfluidic channel frames cover the glass chip. One subunit of the cocaine aptamer is immobilized on the gold surface of a working electrode desired for cocaine detection. The second subunit of the aptamer is immobilized on gold nanoparticles (Au-NP). These marked Au-NP are pumped together with the cocaine solution into the chip system for detection. In case of cocaine binding, an agglomerate is formed at the electrode surface consisting of the cocaine molecule bound between the two subunits of the cocaine aptamer together with the Au-NP load bearing some more aptamer subunits. Subsequently, the electrochemical probe $\left[\mathrm{Ru}\left(\mathrm{NH}_{3}\right)_{6}\right]^{3+}$ (RuHex) binds to the surface-confined DNA via electrostatic interaction and is measured by chronocoulometry. The Au-NP are used to produce an amplified electrochemical signal and improve the sensitivity of the sensor. The detection limit for cocaine of this sensor is $70 \mathrm{nM}$ and the linear range is 0.1 to $26.3 \mu \mathrm{M}$ [130].

Freeman et al. [143] showed three different possibilities to use the self-assembling cocaine aptamer subunits [79]. The electrochemical cocaine detection by use of these subunits and a methylene blue label is described here; the optical methods based on FRET and excimer fluorescence are described in the following chapter "Optical test systems: biosensors and assays." The electrochemical cocaine aptamer sensor consists of the thiol-modified aptamer subunit C2-D from [79] immobilized on a gold electrode and the methylene blue $\left(\mathrm{MB}^{+}\right)$- modified subunit $\mathrm{F}-\mathrm{C} 1$ [79]. Linear sweep voltammograms were measured by use of a graphite counter electrode and a saturated calomel reference electrode (SCE). In the absence of cocaine, a low intensity voltammetric response is observed, which might be attributed to a minute nonspecific binding of the $\mathrm{MB}^{+}$to the electrode surface [143]. In the presence of cocaine, the synergistically stabilized supramolecular complex, consisting of cocaine and both aptamer subunits, is formed on the electrode surface. The confinement of the redox label (methylene blue) at the electrode surface enables an electrochemical readout of the formation of the cocaine aptamer complex correlating to the cocaine concentration [143]. The detection limit of this sensor equates to $10 \mu \mathrm{M}$, the linear measuring range is $10 \mu \mathrm{M}$ to $1 \mathrm{mM}$. Other studies have reported the electrochemical detection of analytes by a redoxlabeled aptamer, which is immobilized on the electrode. After addition of the analyte (target), the aptamer-target binding causes structural alignment of the redox label in respect to the electrode $[82,143,144]$. In the absence of the analyte this electrode arrangement of the redox label causes a large electrical background response whereas the structural rearrangement caused by the presence of analyte only leads to small voltammetric changes [143].

A label-free electrochemical aptasensor was constructed by use of a layer-by-layer self-assembled multilayer with ferrocene-appended poly(ethyleneimine) (Fc-PEI) on an indium tin oxide (ITO) array electrode [145]. Ferrocene is the redox mediator which is incorporated in the electrode surface. Fc-PEI and gold nanoparticles (Au-NP) are assembled layer by layer on the electrode surface. The cocaine aptamer fragments from [79] are used. One cocaine aptamer fragment, which is labeled with a SH-group, is coupled to the outermost Au-NP layer. The other cocaine aptamer fragment is able to hybridize partly with the first aptamer fragment and binds to the target cocaine. This binding causes a decreasing in the differential pulse voltammetry signal of Fc-PEI. The big advantage of this sensor construction is the incorporation of the electrode mediator in the electrode surface. The sensor has a linear range of $0.1 \mu \mathrm{M}$ to $38.3 \mu \mathrm{M}$ and a detection limit of $0.1 \mu \mathrm{M}$. It was applied in spiked real samples of human plasma, human serum, human saliva, and human urine $(25 \%$ biological fluids). The recovery of $3.8 \mu \mathrm{M}$ cocaine in the $25 \%$ biological fluids was between 101.4 and $105.8 \%$ and 96.1 and $102.7 \%$, respectively, which means that the measurement of cocaine in biological fluids is possible by use of this aptasensor.

Electrogenerated chemiluminescence (ECL) technique was used with the cocaine aptamer F7.9D from [80] labeled at its $3^{\prime}$ terminus with the ruthenium complex $\mathrm{Ru}(\mathrm{bpy})_{2}$ (dcbpy) NHS [146]. This aptamer is immobilized onto a gold electrode surface via thiol-Au interactions. As in some other applications, the cocaine aptamer [80] remains partially unfolded in the absence of target, resulting in a small ECL signal due to the distance between electrode surface and tag. In the presence of target, the aptamer folds in the three-way junction structure and thus a strong ECL signal is measured due to the tag moving closer to the electrode surface. The ECL signal is generated by polarization of the electrode to $+0.8 \mathrm{~V}$ in $0.1 \mathrm{M}$ phosphate-buffered saline (PBS) containing $0.1 \mathrm{M}$ tripropylamine (TPA). Sensor characteristics are the detection limit of $1 \mathrm{nM}$ cocaine, a linear measuring range of $5 \mathrm{nM}$ to $0.3 \mu \mathrm{M}$ cocaine, and no cross-reactivity to heroin and caffeine. The sensor is regenerable in $2 \mathrm{ml}$ of $0.10 \mathrm{M}$ PBS ( $\mathrm{pH} \mathrm{7.40)} \mathrm{for} \mathrm{four} \mathrm{minutes} \mathrm{with} \mathrm{two} \mathrm{times} \mathrm{and} \mathrm{by}$ extensively washing with water according to [82]. Long-term storage stability was proved by storage at $4{ }^{\circ} \mathrm{C}$ over 10 days, with no significant change of the measuring signal for $50 \mathrm{nM}$ cocaine [146].

In a subsequent work an electrogenerated chemiluminescence (ECL) sensor for cocaine detection uses the cocaine aptamer labeled with a ruthenium derivative (cocaine aptamer-Ru1) [147]. The 30-mer cocaine aptamer from Baker et al. [82], which is in fact based on the cocaine aptamer described by Stojanovic et al. [80], was modified with spacers and the Rul complex (which is not specified in the article). The cocaine aptamer-Rul is covalently coupled to the surface of a paraffin-impregnated graphite electrode that had been covalently modified with a monolayer of 4-aminobenzene sulfonic acid using electro- 
chemical oxidation. ECL-based detection of cocaine was performed with a potential-step excitation from an initial potential of $0 \mathrm{~V}$ to a constant potential $+1.35 \mathrm{~V}$ vs. $\mathrm{Ag} / \mathrm{AgCl}$ in a $0.1 \mathrm{M}$ TPA-0.1 M PBS ( $\mathrm{pH}$ 7.4) solution. As described above, the cocaine aptamer folds in the well-known threeway junction structure with cocaine binding, which brings the Ru 1 modification nearer to the electrode. Quantification of cocaine is based on the ECL peak intensity change. The ECL emissions were detected with a photomultiplier tube. With this cocaine aptamer-Ru1-based sensor, the binding constant between cocaine and its aptamer was estimated to be $4.6 \pm 0.3 \mathrm{nM}$ [147]. The selectivity was tested with caffeine and heroin, which did not interfere with cocaine. The sensor was reusable $(\mathrm{RSD}=2.8 \%, n=7)$ and had a good long-term storage stability at $4{ }^{\circ} \mathrm{C}$ (recovery of $96.8 \%$ and $92.3 \%$ after 21 and 30 days). This cocaine sensor has a detection limit of $10 \mathrm{pM}$ for cocaine, which is 2 orders of magnitude lower than that of the above mentioned ECL cocaine aptamer sensor with self-assembled aptamer$\mathrm{Ru}(\mathrm{bpy})_{3}{ }^{2+}[146]$.

\section{Hormones}

An electrochemical aptasensor for $17 \beta$-estradiol consists of the DNA aptamer-modified gold working electrode chip (eight electrodes in parallel) using the biotin-streptavidin coupling system, a platinum counter electrode, and an $\mathrm{Ag} /$ $\mathrm{AgCl}$ reference electrode [102]. $\mathrm{K}_{3} \mathrm{Fe}(\mathrm{CN})_{6}$ is used in solution as the electron mediator. $\mathrm{CV}$ and $\mathrm{SWV}$ are used for the measurement of the redox reaction between ferrocyanide and ferricyanide. Binding of $17 \beta$-estradiol molecules to the aptamers causes measurable changes in electrical current. The linear range of the biosensor was 0.01 to $1 \mathrm{nM}$ $17 \beta$-estradiol [102].

Optical test systems: biosensors and assays

Optical signals such as fluorescence and color are preferred for affinity-based recognition in biosensors because they are easily detectable with high sensitivity and minimal instrumentation. Fluorescence-based detection found growing interest for real-time in-field measurement because of recent advances in miniaturization of the fluorescence excitation sources and emission detectors [16].

The signals of colorimetric sensors and assays can be detected by the naked eye under some circumstances. By this way, the need of instruments is eliminated which makes the application easier for unskilled personnel and household application [16].

$\mathrm{Au}-\mathrm{NP}$ possess a number of useful properties, such as very high extinction coefficients and distance dependent color display (aggregated particles are blue or purple, dispersed particles are red). Highly sensible and simple tests like colorimetric assays or lateral flow-based test strips can be constructed [16]. For competitive aptamer-based AuNP colorimetric sensors, the affinity ratio of the aptamers to both unmodified Au-NP and target $\left(K_{\mathrm{D} \text { (AuNP) }} / K_{\mathrm{D} \text { (Target) }}\right)$ was detected as a tool to design more sensitive small molecule detection systems [148]. The lateral flow technology is used in some common applied antibody tests, as the well-known commercially available pregnancy test kit. The user friendliness of this format allows its application by users without laboratory background. No precise transformation of solutions is necessary. The result is shown more or less as a "yes/no" answer, but with clear discrimination because of the negative controls incorporated. Such a lateral flow system is described for aptamer nanoparticle-based disaggregation reaction for cocaine detection [149].

\section{Pharmaceuticals with psychotropic effects}

The frequently used cocaine aptamer was introduced by Stojanovic and coworkers in the years 2000 to 2002 with three assays. At first, an aptamer self-assembly with fluorescence quenching was described [79]. In this case, the aptamer sequence was divided in two subunits: One (named C2-D) is labeled with a $3^{\prime}$-dabcyl quencher and the other (named F-C1) with 5'-6-carboxy-fluorescein fluorophore [79]. The two subunits behaved as a self-assembling fluorescent cocaine assay, which was able to report cocaine concentrations in the range of 10 to $1250 \mu \mathrm{M}$ in the respective selection buffer solution [79]. The fluorescein emission at $518 \mathrm{~nm}\left(\lambda_{\mathrm{ex}}=472 \mathrm{~nm}\right)$ was quenched to $65 \%$ of the initial value with $1 \mathrm{mM}$ cocaine. The assay showed selectivity for cocaine over its metabolites benzoyl-ecgonin and ecgonine methyl ester [79].

The second assay is based on the cocaine aptamer MNS4.1 [80]. MNS-4.1 consists of three stems S1, S2, S3 with the assumed cocaine binding pocket located in the lipophilic cavity in the center of the three-way junction structure. They engineered an instability in one of the stems of this aptamer which results in a structure that is dependent on the stabilization provided by ligand binding to form the three-way junction. Double end labeling of the opened stem with $5^{\prime}$-fluorescein fluorophore and 3'-dabcyl as quencher resulted in the F7.9D cocaine aptamer. This assay operates for cocaine detection in serum in the micromolar range $(10 \mu \mathrm{M}$ to $4 \mathrm{mM})$ and is characterized by a dissociation constant of $\sim 100 \mu \mathrm{M}$ [80]. In their third article, Stojanovic and Landry [81] introduced a colorimetric dye displacement assay. The cocaine aptamer MNS-4.1 [80] is incubated with the cyanine dye diethylthiatricarbocyanine iodide, which complexed to the aptamer in the sequence region of the cocaine binding pocket. In the presence of cocaine, the dye is replaced and cocaine binds to the aptamer. A change in the absorption spectra of the dye can be detected depending 
on cocaine concentration. The authors stated that the sensitivity and selectivity of this colorimetric assay was slightly better than that of the corresponding fluorescent assay for cocaine [80, 81].

An assay based on the same aptamer subunits from [79] was described which makes use of the quantum dots (QDs) stimulated fluorescence resonance energy transfer reaction in connection with aptamer-target binding and formation of the stable cocaine-aptamer supramolecular structure [143]. $\mathrm{CdSe} / \mathrm{ZnS}$ quantum dots were bound to the C2-D subunit of the cocaine aptamer [79], and the Atto 590 dye was bound to the F-C1 subunit from [79]. In the presence of cocaine, the supramolecular cocaine-aptamer complex is synergistically stabilized by the base pairing of the tethered chains, giving rise to the stable cocaine-aptamer supramolecular structure. This results in the FRET process between the QDs and the dye acceptor [143]. Luminescence spectra were measured and the assay was characterized by a detection limit of $1 \mu \mathrm{M}$ and a linear measuring range up to $1 \mathrm{mM}$ cocaine [143]. In a further variation, the authors use the formation of the pyrene excimer structure and its characteristic fluorescence. Pyrene molecules are bound to both aptamer subunits. In the absence of cocaine, the fluorescence spectra are characterized by pyrene monomer emission peaks. Upon the addition of cocaine, the fluorescence of pyrene monomers decreases, and the characteristic fluorescence of the pyrene excimer at $\lambda=480 \mathrm{~nm}$ is observed. This assay showed a detection limit of $100 \mu \mathrm{M}$ and a linear measuring range up to $1 \mathrm{mM}$ cocaine [143].

For fast colorimetric sensing, a general sensor design based on aptamers and gold nanoparticles was described [126]. The big advantage of simple colorimetric assays is that they render analytical instruments unnecessary what makes the test easier and cheaper in most cases. The optical properties of metallic nanoparticles are characterized by their distance dependence and high extinction coefficients. Thus, they were used for DNA-related colorimetric assays based on Watson-Crick base pairing [150]. Aptamers may be also used in combination with Au nanoparticles [151]. A more general method for sensor design was described for cocaine detection based on the reported cocaine aptamer [80], with slight modifications [126]. The sensing principle is based on the disassembly of Au nanoparticle aggregates by binding of cocaine to the aptamer. The nanoparticle aggregates containing three components [126]: a linker DNA, representing the aptamer with a sequence extension at the 5'-end and two thiol-modified oligonucleotides, which are coupled to separate $\mathrm{Au}$ nanoparticles and are both complementary to the 5 '-region of the linker DNA. So the linker connects the two thiol-modified sequences and aggregates the two types of $\mathrm{Au}$ nanoparticles. In solution, these aggregates show a faint purple color. When cocaine is added, the aptamer changes its configuration with binding to cocaine. The linking between the two types of nanoparticles opens up and the nanoparticles dissociate away from each other, which causes a color change from purple to red. This color change is concentration dependent. Cocaine concentrations in the range between 50 and $500 \mu \mathrm{M}$ were detected by use of this assay [126]. The detection of cocaine in the environment (e.g., in river water) by aptamer biosensors was not described until now.

An aptamer-based cocaine assay was developed in our group with the aim for application in environmental analytics. In this case, the DNA cocaine aptamer [79-81] was modified with markers for FRET-based detection of the binding reaction by intermolecular aptamer beacon formation. The modifications of the aptamer sequence were done in the style of Liu et al. [126] whereas an additional fluorescence marker was added at the 5 '-end. The aptamer works in this assay in connection with a second complementary oligonucleotide which bears a DABCYL quencher at the 3 '-end (see Table 3). Figure 1 shows the function of this aptamer-based cocaine assay. The measuring solution contains two DNA molecules-the aptamer and the quencher oligomer. In the absence of cocaine, the aptamer has a partial unfolded structure, and the quencher oligomer is able to hybridize to the aptamer. Fluorophore and quencher come into close proximity. Energy transfer from the excited fluorophore to the quencher molecule takes place and causes fluorescence deletion. The fluorescence in the measuring solution reaches a minimum. In the presence of cocaine, the aptamer folds in the typical three-way junction structure and a stable aptamer-binding complex is formed. The quencher oligomer is displaced from the aptamer

Table 3 Sequences of the cocaine aptamer (original [79-81] and modified [152]) and quencher oligonucleotide [152] used for a cocaine assay with FRET-based detection

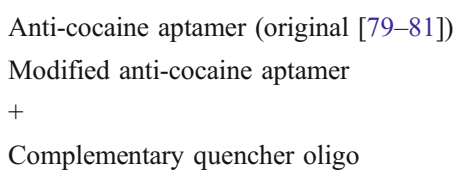

5'-GGGAGACAAGGATAAATCCTTCAATGAAGTGGGTCGACA-3'

$39 \mathrm{nt}$ 5'-Fl-ATCTCGGGAGACAAGGATAAATCCTTCAATGAAGTGGGTCTCCC-3' 5'-GTCTCCCGAGAT-D-3'
$44 \mathrm{nt}$

$12 \mathrm{nt}$

The functionality of the assay is depicted in Fig. 1. Letters in bold are added nucleotides, letters in italic are replaced nucleotides, and underlined are complementary sequence parts of the aptamer

Fl Fluorescein marker, D Dabcyl marker 
Fig. 1 Functionality of a FRET-based cocaine assay by use of the modified cocaine aptamer and a quencher oligonucleotide [152]. In the absence of cocaine, the quencher oligomer is able to hybridize to the partially unfolded aptamer. Fluorophore and quencher come into close proximity and fluorescence is deleted. The fluorescence in the measuring solution reaches a minimum. In the presence of cocaine, the aptamer folds in the typical three-way junction forming a stable aptamer-binding complex. The quencher oligomer is displaced from the aptamer and released into the surrounding solution. Fluorophore and quencher are now far away from each other. The fluorescence intensity increases in dependence of the cocaine concentration in the measuring solution

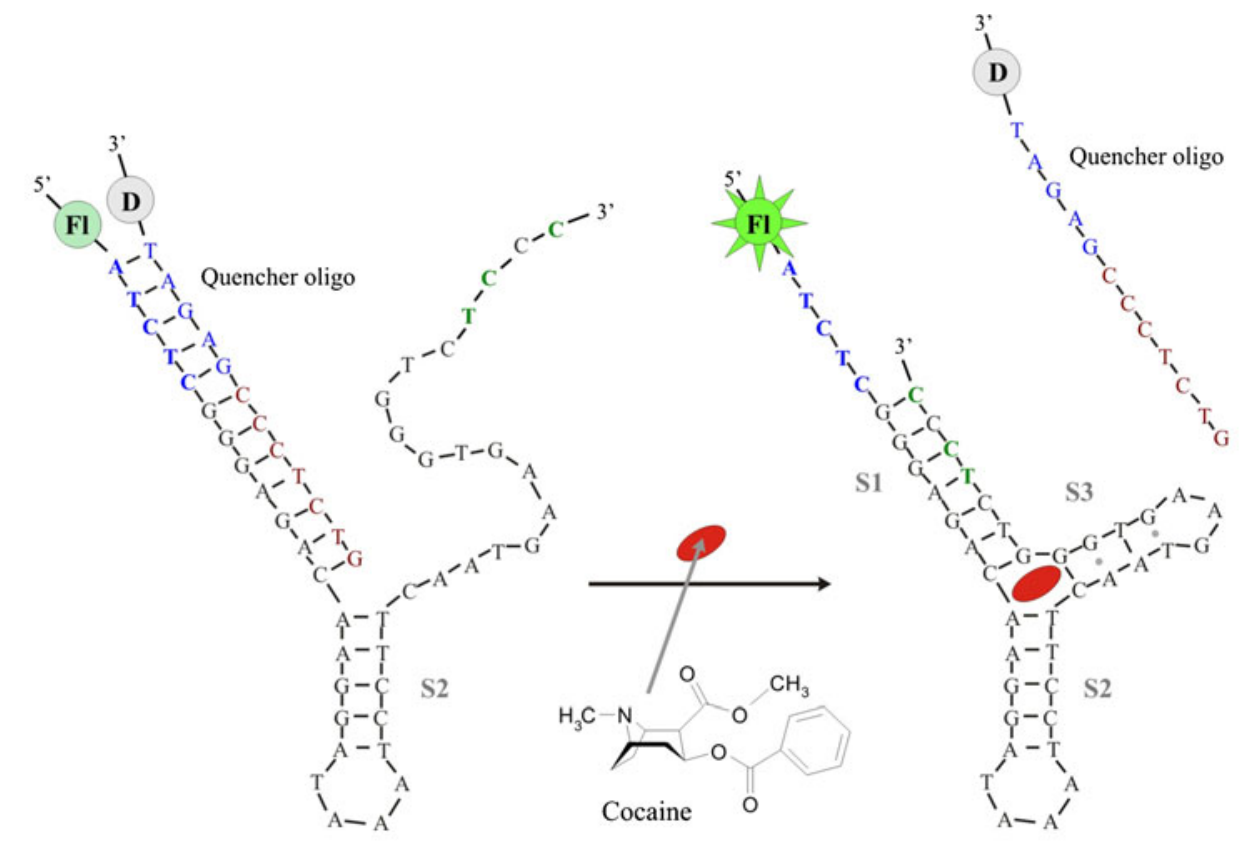

partially unfolded aptamer with only one stem (S2) and hybridised quencher oligo aptamer folded in cocaine-binding three-way junction structure with three stems (S1, S2, S3) and detached quencher oligo

fluorescent assay to detect cocaine based on conformational changes of the anti-cocaine aptamer

FI Fluorophore (quenched fluorescein)

Quencher (DABCYL)

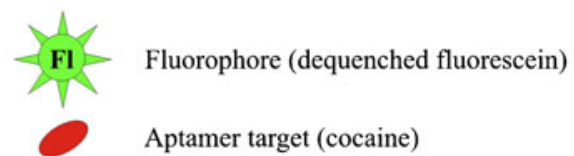

Aptamer target (cocaine) and released into the surrounding solution. Fluorophore and quencher are now far away from each other. The fluorescence intensity increases in dependence of the cocaine concentration in the measuring solution. The functionality of this assay was shown in binding experiments with cocaine concentrations in the range of 0 to $5000 \mu \mathrm{M}$ cocaine (Fig. 2). The detection limit for cocaine was $10 \mu \mathrm{M}$, and the linear range was $10 \mu \mathrm{M}$ to $1 \mathrm{mM}$ cocaine. Non-linear regression analysis of the binding results was used for calculation of the $K_{\mathrm{D}}$ value which was determined to be $134.4 \pm 7.2 \mu \mathrm{M}$ (Fig. 2) for the aptamer in this assay [152].

Another colorimetric assay for cocaine is also readable by the naked eye [153]. Two fragments of the cocaine aptamer [80] are used. One is thiolated and covalently bound to amine-functionalized magnetic nanoparticles (MNP). The other fragment is labeled with a G-quadruplex DNAzyme which can bind hemin and possesses peroxidase-like activity. This DNAzyme can catalyze the $\mathrm{H}_{2} \mathrm{O}_{2}$-mediated oxidation of 3,3,5,5-tetramethylbenzidine sulfate (TMB). The same reaction catalyzed by horseradish peroxidase (HRP) is often used in colorimetric assays, for instance ELISA tests, because of

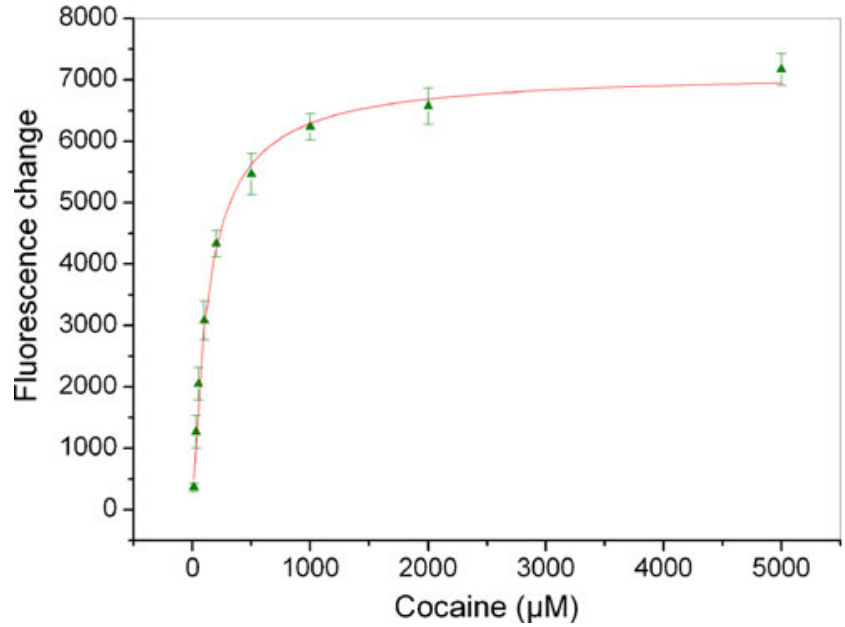

Fig. 2 Measuring curve for cocaine detection by measurement of fluorescence change in the aptamer-based cocaine assay (Fig. 1), c [cocaine] $=0-5 \mathrm{mM}$ [152]. The saturation curve was used for the determination of $K_{\mathrm{D}}=134.4 \pm 7.2 \mu \mathrm{M}$ by non-linear regression analysis 
its sensitive color change. When all three, the magnetic beads bearing one aptamer fragment, the other aptamer fragment conjugated with the DNAzyme, and cocaine come into contact in the measuring solution, cocaine binds to the aptamer strands which fold into the three-way junction structure on the surface of MNPs. The MNPs could be separated from the excess of aptamer fragment-DNAzyme complexes in solution by use of an external magnet. Afterwards, hemin is added to the MNPs solution which causes formation of the DNAzyme, which effectively catalyzes the $\mathrm{H}_{2} \mathrm{O}_{2}$-mediated oxidation of TMB, giving rise to a change in solution color. In the absence of cocaine, the DNAzyme-conjugated aptamer fragment does not bind to the MNP; thus, no background signal caused by this effect can be found [153]. The color change of TMB as the measuring signal was detected by the naked eye or by measuring the absorption after terminating the TMB- $\mathrm{H}_{2} \mathrm{O}_{2}$ reaction by addition of $1 \mathrm{M} \mathrm{H}_{2} \mathrm{SO}_{4}$. The assay has a linear range from $100 \mathrm{nM}$ to $20 \mu \mathrm{M}$ cocaine and a detection limit of $50 \mathrm{nM}$. Selectivity was checked with methadone, ecgonine, and pethidine which did not show an observable color change compared to the background [153]. The assay was tested for application in human plasma, serum, and urine. It provides a simple experimental process, low background signal, and good selectivity. Its detection limit $(50 \mathrm{nM})$ is lower than that of most colorimetric cocaine aptamer sensors or tests.

A "dipstick" test based on the same Au-NP - cocaine aptamer [79-81] — linker—based assembly [126] was described in [149]. Additionally, some nanoparticles were modified with biotin for capturing using streptavidin. The dipstick consisted of four pads: the wicking pad which is dipped in the solution to be tested. The following conjugation pad is loaded with the Au nanoparticle-cocaine aptamer aggregates which are of purple color. Test solution without cocaine causes no disaggregation, and the aggregates do not change their color and are not able to leave the conjugation pad. Cocaine in the test solution causes disaggregation, and the smaller scattered nanoparticles with aptamer-bound cocaine are able to diffuse into the membrane pad. This membrane is loaded with a stripe of streptavidin. The biotinmarked nanoparticles are captured within this stripe giving a red color because of their disaggregated state. The following absorption pad collects all the remaining nanoparticles, which are not captured by streptavidin, resulting in a slightly red color. The detection limit for cocaine in buffer solution was determined to be $10 \mu \mathrm{M}$. This lateral flow assay was also used for determination of cocaine in untreated human blood serum. In this case, $10 \mu \mathrm{l}$ of the serum sample was added directly to the conjugation pad to rehydrate and react with the nanoparticle aggregates. After $20 \mathrm{~s}$, the wicking pad was dipped into running buffer solution. The sensitivity in serum was 20 times lower compared to that in buffer solution [149]. This lateral flow method should be a general approach adaptable to other aptamers, as far as the target binding causes a structure switch of the aptamer so that the nanoparticle disaggregation can take place as described in [126].

A sensitive fluorescence-based method for quantitative cocaine detection is based on an aptamer and rolling circle amplification [154]. A cocaine binding aptamer which is in its core region very similar to that described in [80] was used. The aptamer was immobilized at Au-NP which were bound to magnetic beads. A short DNA strand with structure compatibility to a part of the aptamer sequence was hybridized to the aptamer. In the presence of cocaine, the short DNA strand was displaced from aptamer owing to the cocaine aptamer binding. Next, the short DNA strand was separated by magnetic beads and used to originate rolling circle amplification as primer. The end products of rolling circle amplification were detected by fluorescence signal generation upon molecular beacons hybridizing with the end products of rolling circle amplification. Cocaine was detected in the range of $0.5 \mathrm{nM}$ to $1.0 \mu \mathrm{M}$ by fluorescence measurement, with a detection limit of $0.48 \mathrm{nM}$ cocaine and a linear range of the assay from 1 to $50 \mathrm{nM}$ [154]. Compared to other aptamer-based assays and sensors for cocaine detection, this method possesses a very good sensitivity. However, its practical use is limited because its mode of operation is more complicated.

\section{Hormones}

An optofluidic surface-enhanced Raman spectroscopy (SERS) device for on chip detection of vasopressin based on an L-DNA aptamer developed by Williams et al. [116] was described [155]. Vasopressin was fluorescein isothiocyanate (FITC)-labeled, and the aptamer was incorporated in a metallic multilayer nanotube SERS active substrate. SERS signals from the FITC-labeled vasopressin which was bound to the incorporated aptamers were measured. The detection limit was $5.2 \mu \mathrm{U} / \mathrm{ml}$ vasopressin in PBS buffer solution.

A competitive ELAA for dopamine detection in serum was developed by use of the RNA aptamer for dopamine $[61,156]$. The aptamer was 3'-biotin-labeled. The ELAA consists of the immobilization of the biotin-labeled aptamer in the wells of a neutravidin-coated microtiter plate. Dopamine is added to the wells, and the plate is incubated at $4{ }^{\circ} \mathrm{C}$ for $1 \mathrm{~h}$ while shaking. Afterward, dopamine-HRP conjugate in assay buffer is added and incubated at $4{ }^{\circ} \mathrm{C}$ for $15 \mathrm{~min}$ at room temperature. Unbound dopamine-HRP conjugate is removed by washing. TMB in substrate buffer is added to each well and incubated for $10 \mathrm{~min}$ at room temperature. The color development is stopped by $2 \mathrm{M}$ $\mathrm{H}_{2} \mathrm{SO}_{4}$, and absorbance is measured at $450 \mathrm{~nm}$ [156]. The assay conditions for the competitive ELAA method were optimized for dopamine detection in serum. The test is characterized by a limit of detection of $1 \mathrm{pM}$ and a dynamic 
range of $50 \mathrm{pM}$ to $0.1 \mu \mathrm{M}$ dopamine. Tests showed some cross-reactivity to norepinephrine $(3.68 \%)$, whereas 3 methoxytyramine, epinephrine, homovanillic acid, and 3,4dihydroxyphenylacetic acid showed very little cross-reactivity $(<1 \%)$ [156]. In comparison to an ELISA method that uses antibodies, the ELAA is more selective and sensitive and shows a better linear range. It should be mentioned that Walsh and DeRosa demonstrated that the DNA homolog of the RNA aptamer which was used in this ELAA assay is able to bind dopamine with improved affinity and similar specificity [157], but was not tested in the ELAA assay until now.

\section{Conclusions}

The astonishing broad range of pharmaceuticals for which aptamers were developed includes mainly antibiotics (RNA and DNA aptamers), psychotropics (RNA and DNA aptamers), analgetics (DNA aptamers), and hormones (DNA aptamers). The aim of RNA aptamer development for pharmaceuticals was often to elucidate the mechanism of action of a specific drug, whereas DNA aptamer development was dedicated to detection of pharmaceuticals in clinical diagnostics.

Biosensors and assays based on aptamers were developed mostly using optical and electrochemical detection of the binding signal between aptamer and target. For the detection of antibiotics, mainly electrochemical detection was described, whereas the cocaine aptamer is used in a big variety of electrochemical and optical sensors and assays. The structure of the cocaine aptamer with its unique sequence forming a three-way junction and the corresponding structure switch on target binding make it particularly suitable as a model aptamer for the development of sensors and assays. Particularly noticeable for the cocaine aptamer-based systems is the generally higher sensitivity of electrogenerated chemiluminescence over electrochemical sensors and over other optical assays.

Aptamer-based sensors and assays for the detection of pharmaceuticals were, until now, developed generally either as model systems or aiming at the application in clinical diagnostics for the detection of drugs in human blood, serum, or urine. The use of aptamers for environmental application, especially for the detection of pharmaceutical residues in surface and ground waters, is not yet in the focus of the development of biosensors and assays. Only in a few articles the application of pharmaceutical-specific aptamers as affinity tags for enrichment and purification is mentioned.

However, the health risk of pharmaceuticals in the environment, which are found mostly in very small concentrations but with permanent exposure to humans and animals, is not yet adequately explored. Consolidated knowledge about emission, distribution, degradation, formation of metabolites, and adverse environmental effects is needed. The development of alternative measuring systems for online and in-field pharmaceuticals detection is necessary. Aptamer-based sensors and assays could be an alternative to the conventional methods of chemical analysis.

Acknowledgments Funding by Arbeitsgemeinschaft industrieller Forschungsvereinigungen e.V. (AiF) Pro INNO II (KF 0011004DA6) and Federal Ministry of Education and Research (01RB0805B and 03X0094B) is kindly acknowledged. We thank Nadia Nikolaus for helpful discussion and critical reading of the manuscript.

Open Access This article is distributed under the terms of the Creative Commons Attribution Noncommercial License which permits any noncommercial use, distribution, and reproduction in any medium, provided the original author(s) and source are credited.

\section{References}

1. Hermann T, Patel DJ (2000) Adaptive recognition by nucleic acid aptamers. Science 287(5454):820-825

2. Stoltenburg R, Reinemann C, Strehlitz B (2007) SELEX-A (r) evolutionary method to generate high-affinity nucleic acid ligands. Biomol Eng 24(4):381-403

3. Tuerk C, Gold L (1990) Systematic evolution of ligands by exponential enrichment: RNA ligands to bacteriophage T4 DNA polymerase. Science 249(4968):505-510

4. Ellington AD, Szostak JW (1990) In vitro selection of RNA molecules that bind specific ligands. Nature 346(6287):818-822

5. Ellington AD, Szostak JW (1992) Selection in vitro of singlestranded DNA molecules that fold into specific ligand-binding structures. Nature 355(6363):850-852

6. Sun S (2000) Technology evaluation: SELEX, Gilead Sciences Inc. Curr Opin Mol Ther 2(1):100-105

7. Djordjevic M (2007) SELEX experiments: new prospects, applications and data analysis in inferring regulatory pathways. Biomol Eng 24(2):179-189

8. Gopinath SCB (2007) Methods developed for SELEX. Anal Bioanal Chem 387(1):171-182

9. Klug SJ, Famulok M (1994) All you wanted to know about SELEX. Mol Biol Rep 20(2):97-107

10. Mairal T, Ozalp VC, Lozano Sanchez P, Mir M, Katakis I, O'Sullivan CK (2008) Aptamers: molecular tools for analytical applications. Anal Bioanal Chem 390(4):989-1007

11. Lee JF, Stovall GM, Ellington AD (2006) Aptamer therapeutics advance. Curr Opin Chem Biol 10(3):282-289

12. Tucker CE, Chen LS, Judkins MB, Farmer JA, Gill SC, Drolet DW (1999) Detection and plasma pharmacokinetics of an antivascular endothelial growth factor oligonucleotide-aptamer (NX1838) in rhesus monkeys. J Chromatogr B 732(1):203-212

13. Chapman JA, Beckey C (2006) Pegaptanib: a novel approach to ocular neovascularization. Ann Pharmacother 40(7-8):13221326

14. Maberley D (2005) Pegaptanib for neovascular age-related macular degeneration. Issues Emerg Health Technol (76):1-4

15. Siddiqui MAA, Keating GM (2005) Pegaptanib - in exudative age-related macular degeneration. Drugs 65(11):1571-1577

16. Wernette DP, Liu JW, Bohn PW, Lu Y (2008) Functional-DNAbased nanoscale materials and devices for sensing trace contaminants in water. MRS Bull 33(1):34-41 
17. Kern K (2010) Rechtliche Regulierung der Umweltrisiken von Human- und Tierarzneimitteln (Vol. 8, Berliner Stoffrechtliche Schriften). Lexxion Verlagsgesellschaft, Berlin

18. Hansen PD, Dizer H, Hock B, Marx A, Sherry J, McMaster M et al (1998) Vitellogenin - a biomarker for endocrine disruptors. Trac-Trends in Analytical Chemistry 17(7):448-451

19. Bundesministeriums für Gesundheit und Umweltbundesamt (2005) Bericht des Bundesministeriums für Gesundheit und des Umweltbundesamtes an die Verbraucherinnen und Verbraucher über die Qualität von Wasser für den menschlichen Gebrauch (Trinkwasser) in Deutschland. Bundesministeriums für Gesundheit und Umweltbundesamt, Bonn

20. Ternes TA, Siegrist H, Berthold G (2005) Arzneimittelrückstände: ein Problem für die nächste Generation? Eine zusammenfassende Betrachtung. In: Umweltbundesamt (ed) Arzneimittel in der Umwelt $-\mathrm{Zu}$ Risiken und Nebenwirkungen fragen Sie das Umweltbundesamt (29/05). UBA-Texte, Dessau, pp 101-113

21. Tombelli S, Mascini M (2010) Aptamers biosensors for pharmaceutical compounds. Comb Chem High Throughput Screen 13(7):641-649

22. Kim M, Um HJ, Bang S, Lee SH, Oh SJ, Han JH et al (2009) Arsenic removal from Vietnamese groundwater using the arsenicbinding DNA aptamer. Environ Sci Technol 43(24):9335-9340

23. Noller HF (1991) Ribosomal RNA and translation. Annu Rev Biochem 60:191-227

24. Kohanski MA, Dwyer DJ, Collins JJ (2010) How antibiotics kill bacteria: from targets to networks. Nat Rev Microbiol 8(6):423-435

25. Schroeder R, Waldsich C, Wank H (2000) Modulation of RNA function by aminoglycoside antibiotics. EMBO J 19(1):1-9

26. Tor Y, Hermann T, Westhof E (1998) Deciphering RNA recognition: aminoglycoside binding to the hammerhead ribozyme. Chem Biol 5(11):R277-R283

27. Wang Y, Rando RR (1995) Specific binding of aminoglycoside antibiotics to RNA. Chem Biol 2(5):281-290

28. Wang Y, Killian J, Hamasaki K, Rando RR (1996) RNA molecules that specifically and stoichiometrically bind aminoglycoside antibiotics with high affinities. Biochemistry 35 (38): $12338-12346$

29. Jiang L, Suri AK, Fiala R, Patel DJ (1997) Saccharide-RNA recognition in an aminoglycoside antibiotic-RNA aptamer complex. Chem Biol 4(1):35-50

30. Jiang L, Patel DJ (1998) Solution structure of the tobramycinRNA aptamer complex. Nat Struct Biol 5(9):769-774

31. Hamasaki K, Killian J, Cho J, Rando RR (1998) Minimal RNA constructs that specifically bind aminoglycoside antibiotics with high affinities. Biochemistry 37(2):656-663

32. Cho JY, Hamasaki K, Rando RR (1998) The binding site of a specific aminoglycoside binding RNA molecule. Biochemistry 37(14):4985-4992

33. Morse DP (2007) Direct selection of RNA beacon aptamers. Biochem Biophys Res Commun 359(1):94-101

34. Vandenengel JE, Morse DP (2009) Mutational analysis of a signaling aptamer suggests a mechanism for ligand-triggered structure-switching. Biochem Biophys Res Commun 378 (1):51-56

35. Wallis MG, von Ahsen U, Schroeder R, Famulok M (1995) A novel RNA motif for neomycin recognition. Chem Biol 2(8):543-552

36. Jiang LC, Majumdar A, Hu WD, Jaishree TJ, Xu WK, Patel DJ (1999) Saccharide-RNA recognition in a complex formed between neomycin B and an RNA aptamer. Structure 7(7):817-827

37. Cowan JA, Ohyama T, Wang DQ, Natarajan K (2000) Recognition of a cognate RNA aptamer by neomycin B: quantitative evaluation of hydrogen bonding and electrostatic interactions. Nucleic Acids Res 28(15):2935-2942

38. Stampfl S, Lempradl A, Koehler G, Schroeder R (2007) Monovalent ion dependence of neomycin $\mathrm{B}$ binding to an
RNA aptamer characterized by spectroscopic methods. ChemBioChem 8(10):1137-1145

39. Famulok M, Hüttenhofer A (1996) In vitro selection analysis of neomycin binding RNAs with a mutagenized pool of variants of the 16S rRNA decoding region. Biochemistry 35(14):4265-4270

40. Lato SM, Boles AR, Ellington AD (1995) In-vitro selection of RNA lectins - using combinatorial chemistry to interpret ribozyme evolution. Chem Biol 2(5):291-303

41. Kwon M, Chun SM, Jeong S, Yu J (2001) In vitro selection of RNA against kanamycin B. Molecular Cell 11(3):303-311

42. Lato SM, Ellington AD (1996) Screening chemical libraries for nucleic-acid-binding drugs by in vitro selection: a test case with lividomycin. Mol Divers 2(1-2):103-110

43. Wallace ST, Schroeder R (1998) In vitro selection and characterization of streptomycin-binding RNAs: recognition discrimination between antibiotics. RNA 4(1):112-123

44. Tereshko V, Skripkin E, Patel DJ (2003) Encapsulating streptomycin within a small 40-mer RNA. Chem Biol 10(2):175-187

45. Piganeau N, Jenne A, Thuillier V, Famulok M (2000) An allosteric ribozyme regulated by doxycycline. Angew Chem Int Ed 39(23):4369-4373

46. Berens C, Thain A, Schroeder R (2001) A tetracycline-binding RNA aptamer. Bioorg Med Chem 9(10):2549-2556

47. Xiao H, Edwards TE, Ferré-D'Amaré AR (2008) Structural basis for specific, high-affinity tetracycline binding by an in vitro evolved aptamer and artificial riboswitch. Chem Biol 15(10):1125-1137

48. Wallis MG, Streicher B, Wank H, von Ahsen U, Clodi E, Wallace ST et al (1997) In vitro selection of a viomycin-binding RNA pseudoknot. Chem Biol 4(5):357-366

49. Rogers J, Chang AH, von Ahsen U, Schroeder R, Davies J (1996) Inhibition of the self-cleavage reaction of the human hepatitis delta virus ribozyme by antibiotics. J Mol Biol 259 (5):916-925

50. Kim HJ, Kwon M, Yu J (2007) Elucidation of the RNA target of linezolid by using a linezolid-neomycin B heteroconjugate and genomic SELEX. Bioorg Med Chem 15(24):7688-7695

51. Burke DH, Hoffman DC, Brown A, Hansen M, Pardi A, Gold L (1997) RNA aptamers to the peptidyl transferase inhibitor chloramphenicol. Chem Biol 4(11):833-843

52. Schürer H, Stembera K, Knoll D, Mayer G, Blind M, Förster HH et al (2001) Aptamers that bind to the antibiotic moenomycin A. Bioorg Med Chem 9(10):2557-2563

53. Schürer H, Buchynskyy A, Korn K, Famulok M, Welzei P, Hahn U (2001) Fluorescence correlation spectroscopy as a new method for the investigation of aptamer/target interactions. Biol Chem 382(3):479-481

54. Jensen S, Hansen AC (1993) Abuse of codeine separated from over-the-counter drugs containing acetylsalicylic acid and codeine. Int J Legal Med 105(5):279-281

55. Win MN, Klein JS, Smolke CD (2006) Codeine-binding RNA aptamers and rapid determination of their binding constants using a direct coupling surface plasmon resonance assay. Nucleic Acids Res 34(19):5670-5682

56. Barnes PJ (2003) Theophylline: new perspectives for an old drug. Am J Respir Crit Care Med 167(6):813-818

57. Jenison RD, Gill SC, Pardi A, Polisky B (1994) High-resolution molecular discrimination by RNA. Science 263(5152):1425-1429

58. Condray R, Yao JK (2011) Cognition, dopamine and bioactive lipids in schizophrenia. Front Biosci (Schol Ed) 3:298-330

59. Roos RAC (2010) Huntington's disease: a clinical review. Orphanet J Rare Dis 5(1):40

60. Savica R, Rocca WA, Ahlskog JE (2010) When does Parkinson disease start? Arch Neurol 67(7):798-801

61. Mannironi C, Di Nardo A, Fruscoloni P, Tocchini-Valentini GP (1997) In vitro selection of dopamine RNA ligands. Biochemistry 36(32):9726-9734 
62. Zagotto G, Gatto B, Moro S, Sissi C, Palumbo M (2001) Anthracyclines: recent developments in their separation and quantitation. J Chromatogr B: Biomed Sci Appl 764(1-2):161171

63. Alberts DS, Bachur NR, Holtzman JL (1971) The pharmacokinetics of daunomycin in man. Clin Pharmacol Ther 12(1):96-104

64. Wochner A, Menger M, Orgel D, Cech B, Rimmele M, Erdmann VA et al (2008) A DNA aptamer with high affinity and specificity for therapeutic anthracyclines. Anal Biochem 373 (1):34-42

65. Wochner A, Cech B, Menger M, Erdmann VA, Glökler J (2007) Semi-automated selection of DNA aptamers using magnetic particle handling. Biotechniques 43(3):344-353

66. Wochner A, Glokler J (2007) Nonradioactive fluorescence microtiter plate assay monitoring aptamer selections. Biotechniques 42(5):578-582

67. Pastor-Navarro N, Maquieira A, Puchades R (2009) Review on immunoanalytical determination of tetracycline and sulfonamide residues in edible products. Anal Bioanal Chem 395(4):907-920

68. Jorgensen SE, Halling-Sorensen B (2000) Drugs in the environment. Chemosphere 40(7):691-699

69. Niazi JH, Lee SJ, Gu MB (2008) Single-stranded DNA aptamers specific for antibiotics tetracyclines. Bioorg Med Chem 16 (15):7245-7253

70. Niazi JH, Lee SJ, Kim YS, Gu MB (2008) ssDNA aptamers that selectively bind oxytetracycline. Bioorg Med Chem 16(3):12541261

71. White R, Rusconi C, Scardino E, Wolberg A, Lawson J, Hoffman $M$ et al (2001) Generation of species cross-reactive aptamers using "toggle" SELEX. Mol Ther 4(6):567-574

72. Stoltenburg R, Reinemann C, Strehlitz B (2005) FluMag-SELEX as an advantageous method for DNA aptamer selection. Anal Bioanal Chem 383(1):83-91

73. Jin Y, Jang JW, Han CH, Lee MH (2006) Development of immunoassays for the detection of kanamycin in veterinary fields. J Vet Sci 7(2):111-117

74. Song KM, Cho M, Jo H, Min K, Jeon SH, Kim T et al (2011) Gold nanoparticle-based colorimetric detection of kanamycin using a DNA aptamer. Anal Biochem 415(2):175-781

75. Huerta-Fontela M, Galceran MT, Ventura F (2008) Stimulatory drugs of abuse in surface waters and their removal in a conventional drinking water treatment plant. Environ Sci Technol 42(18):6809-6816

76. Kasprzyk-Hordern B, Dinsdale RM, Guwy AJ (2008) The occurrence of pharmaceuticals, personal care products, endocrine disruptors and illicit drugs in surface water in South Wales, UK. Water Res 42(13):3498-3518

77. van Nuijs AL, Pecceu B, Theunis L, Dubois N, Charlier C, Jorens PG et al (2009) Cocaine and metabolites in waste and surface water across Belgium. Environ Pollut 157(1):123-129

78. Zuccato E, Chiabrando C, Castiglioni S, Calamari D, Bagnati R, Schiarea $S$ et al (2005) Cocaine in surface waters: a new evidence-based tool to monitor community drug abuse. Environ Health 4:14

79. Stojanovic MN, de Prada P, Landry DW (2000) Fluorescent sensors based on aptamer self-assembly. J Am Chem Soc 122 (46):11547-11548

80. Stojanovic MN, de Prada P, Landry DW (2001) Aptamer-based folding fluorescent sensor for cocaine. J Am Chem Soc 123 (21):4928-4931

81. Stojanovic MN, Landry DW (2002) Aptamer-based colorimetric probe for cocaine. J Am Chem Soc 124(33):9678-9679

82. Baker BR, Lai RY, Wood MS, Doctor EH, Heeger AJ, Plaxco KW (2006) An electronic, aptamer-based small-molecule sensor for the rapid, label-free detection of cocaine in adulterated samples and biological fluids. J Am Chem Soc 128(10):3138-3139
83. Cekan P, Jonsson EO, Sigurdsson ST (2009) Folding of the cocaine aptamer studied by EPR and fluorescence spectroscopies using the bifunctional spectroscopic probe C. Nucleic Acids Res 37(12):3990-3995

84. Chen J, Jiang J, Gao X, Liu G, Shen G, Yu R (2008) A new aptameric biosensor for cocaine based on surface-enhanced Raman scattering spectroscopy. Chemistry - A European Journal 14(27):8374-8382

85. Swensen JS, Xiao Y, Ferguson BS, Lubin AA, Lai RY, Heeger AJ et al (2009) Continuous, real-time monitoring of cocaine in undiluted blood serum via a microfluidic, electrochemical aptamer-based sensor. J Am Chem Soc 131(12):4262-4266

86. Teo SK, Denny KH, Stirling DI, Thomas SD, Morseth S, Hoberman AM (2004) Effects of thalidomide on developmental, peri- and postnatal function in female New Zealand white rabbits and offspring. Toxicol Sci 81(2):379-389

87. Hashimoto Y (1998) Novel biological response modifiers derived from thalidomide. Curr Med Chem 5(3):163-178

88. Little RF, Wyvill KM, Pluda JM, Welles L, Marshall V, Figg WD et al (2000) Activity of thalidomide in AIDS-related Kaposi's sarcoma. J Clin Oncol 18(13):2593-2602

89. Shoji A, Kuwahara M, Ozaki H, Sawai H (2007) Modified DNA aptamer that binds the (R)-isomer of a thalidomide derivative with high enantioselectivity. J Am Chem Soc 129(5):1456-1464

90. Cleuvers M (2004) Mixture toxicity of the anti-inflammatory drugs diclofenac, ibuprofen, naproxen, and acetylsalicylic acid. Ecotoxicol Environ Saf 59(3):309-315

91. Oaks JL, Gilbert M, Virani MZ, Watson RT, Meteyer CU, Rideout BA et al (2004) Diclofenac residues as the cause of vulture population decline in Pakistan. Nature 427(6975):630 633

92. Shultz S, Baral HS, Charman S, Cunningham AA, Das D, Ghalsasi GR et al (2004) Diclofenac poisoning is widespread in declining vulture populations across the Indian subcontinent. Proc Biol Sci 271(Suppl 6):S458-S460

93. Schwaiger J, Ferling H, Mallow U, Wintermayr H, Negele RD (2004) Toxic effects of the non-steroidal anti-inflammatory drug diclofenac. Part I: Histopathological alterations and bioaccumulation in rainbow trout. Aquat Toxicol 68(2):141-150

94. Joeng CB, Niazi JH, Lee SJ, Gu MB (2009) ssDNA aptamers that recognize diclofenac and 2-anilinophenylacetic acid. Bioorg Med Chem 17(15):5380-5387

95. Evans AM (1992) Enantioselective pharmacodynamics and pharmacokinetics of chiral non-steroidal anti-inflammatory drugs. Eur J Clin Pharmacol 42(3):237-256

96. Nielsen GL, Sorensen HT, Larsen H, Pedersen L (2001) Risk of adverse birth outcome and miscarriage in pregnant users of nonsteroidal anti-inflammatory drugs: population based observational study and case-control study. BMJ 322(7281):266-270

97. Kim YS, Hyun CJ, Kim IA, Gu MB (2010) Isolation and characterization of enantioselective DNA aptamers for ibuprofen. Bioorg Med Chem 18(10):3467-3473

98. Noppe H, Le Bizec B, Verheyden K, De Brabander HF (2008) Novel analytical methods for the determination of steroid hormones in edible matrices. Anal Chim Acta 611(1):1-16

99. Cargouet M, Perdiz D, Mouatassim-Souali A, Tamisier-Karolak S, Levi Y (2004) Assessment of river contamination by estrogenic compounds in Paris area (France). Sci Total Environ 324(1-3):55-66

100. Servos MR, Bennie DT, Burnison BK, Jurkovic A, McInnis R, Neheli T et al (2005) Distribution of estrogens, 17beta-estradiol and estrone, in Canadian municipal wastewater treatment plants. Sci Total Environ 336(1-3):155-170

101. Wagner M, Oehlmann J (2009) Endocrine disruptors in bottled mineral water: total estrogenic burden and migration from plastic bottles. Environ Sci Pollut Res Int 16(3):278-286 
102. Kim YS, Jung HS, Matsuura T, Lee HY, Kawai T, Gu MB (2007) Electrochemical detection of 17[beta]-estradiol using DNA aptamer immobilized gold electrode chip. Biosens Bioelectron 22(11):2525-2531

103. Huy GD, Jin N, Yin BC, Ye BC (2011) A novel separation and enrichment method of 17beta-estradiol using aptamer-anchored microbeads. Bioprocess Biosyst Eng 34(2):189-195

104. Tritos NA, Mantzoros CS (1998) Recombinant human growth hormone: old and novel uses. Am J Med 105(1):44-57

105. Calik P, Balci O, Ozdamar TH (2009) Human growth hormonespecific aptamer identification using improved oligonucleotide ligand evolution method. Protein Expr Purif 69(1):21-28

106. Bruno JG, Carrillo MP, Phillips T, Edge A (2011) Discrimination of recombinant from natural human growth hormone using DNA aptamers. J Biomol Tech 22(1):27-36

107. Ladisch MR, Kohlmann KL (1992) Recombinant human insulin. Biotechnol Prog 8(6):469-478

108. Yoshida W, Mochizuki E, Takase M, Hasegawa H, Morita Y, Yamazaki $\mathrm{H}$ et al (2009) Selection of DNA aptamers against insulin and construction of an aptameric enzyme subunit for insulin sensing. Biosens Bioelectron 24(5):1116-1120

109. Connor AC, Frederick KA, Morgan EJ, McGown LB (2006) Insulin capture by an insulin-linked polymorphic region $\mathrm{G}$ quadruplex DNA oligonucleotide. J Am Chem Soc 128(15):49864991

110. Hammond-Kosack MC, Docherty K (1992) A consensus repeat sequence from the human insulin gene linked polymorphic region adopts multiple quadriplex DNA structures in vitro. FEBS Lett 301(1):79-82

111. Yoshida W, Sode K, Ikebukuro K (2006) Aptameric enzyme subunit for biosensing based on enzymatic activity measurement. Anal Chem 78(10):3296-3303

112. Doris PA (1984) Central cardiovascular regulation and the role of vasopressin: a review. Clin Exp Hypertens A 6(12):21972217

113. Martin GJ, Ehrenreich J (1964) Oxytocin and vasopressin, posterior pituitary hormones. A review. J Germantown Hosp 12:20-31

114. Schapiro H, Britt LG (1972) The action of vasopressin on the gastrointestinal tract. A review of the literature. Am J Dig Dis 17 (7):649-667

115. Chen P (2002) Vasopressin: new uses in critical care. Am J Med Sci 324(3):146-154

116. Williams KP, Liu XH, Schumacher TN, Lin HY, Ausiello DA, Kim PS et al (1997) Bioactive and nuclease-resistant L-DNA ligand of vasopressin. Proceedings of the National Academy of Sciences of the United States of America-Physical Sciences 94 (21):11285-11290

117. Klussmann S, Nolte A, Bald R, Erdmann VA, Furste JP (1996) Mirror-image RNA that binds D-adenosine. Nat Biotechnol 14 (9):1112-1115

118. Gold L, Polisky B, Uhlenbeck O, Yarus M (1995) Diversity of oligonucleotide functions. Annu Rev Biochem 64:763-797

119. Kiesel L (1993) Molecular mechanisms of gonadotrophin releasing hormone-stimulated gonadotrophin secretion. Hum Reprod 8(Suppl 2):23-28

120. Jennings JC, Moreland K, Peterson CM (1996) In vitro fertilisation. A review of drug therapy and clinical management. Drugs 52(3):313-343

121. Leone M, Valenti G (1987) GnRH analogs: experimental and clinical review. Minerva Endocrinologica 12(4):305-316

122. Leva S, Lichte A, Burmeister J, Muhn P, Jahnke B, Fesser D et al (2002) GnRH binding RNA and DNA Spiegelmers: a novel approach toward GnRH antagonism. Chem Biol 9(3):351-359

123. Arola A, Vilar R (2008) Stabilisation of G-quadruplex DNA by small molecules. Curr Top Med Chem 8(15):1405-1415
124. Han H, Hurley LH (2000) G-quadruplex DNA: a potential target for anti-cancer drug design. Trends Pharmacol Sci 21(4):136 142

125. Simonsson T (2001) G-quadruplex DNA structures-variations on a theme. Biol Chem 382(4):621-628

126. Liu JW, Lu Y (2006) Fast colorimetric sensing of adenosine and cocaine based on a general sensor design involving aptamers and nanoparticles. Angew Chem Int Ed 45(1):90-94

127. Vallee-Belisle A, Plaxco KW (2010) Structure-switching biosensors: inspired by Nature. Curr Opin Struct Biol 20(4):518-526

128. O'Sullivan CK (2002) Aptasensors - the future of biosensing. Anal Bioanal Chem 372(1):44-48

129. Scheller FW (2007) From biosensor to biochip. FEBS J 274 (21):5451

130. Du Y, Chen C, Zhou M, Dong S, Wang E (2011) Microfluidic electrochemical aptameric assay integrated on-chip: a potentially convenient sensing platform for the amplified and multiplex analysis of small molecules. Anal Chem 83(5):1523-1529

131. Xiao Y, Lubin AA, Heeger AJ, Plaxco KW (2005) Label-free electronic detection of thrombin in blood serum by using an aptamer-based sensor. Angew Chem Int Ed 44(34):5456-5459

132. Willner I, Zayats M (2007) Electronic aptamer-based sensors. Angew Chem Int Ed Engl 46(34):6408-6418

133. Zuo XL, Song SP, Zhang J, Pan D, Wang LH, Fan CH (2007) A target-responsive electrochemical aptamer switch (TREAS) for reagentless detection of nanomolar ATP. J Am Chem Soc 129 (5):1042-1043

134. Sassolas A, Blum LJ, Leca-Bouvier BD (2009) Electrochemical aptasensors. Electroanalysis 21(11):1237-1250

135. Sadik OA, Aluoch AO, Zhou A (2009) Status of biomolecular recognition using electrochemical techniques. Biosens Bioelectron 24(9):2749-2765

136. Cash KJ, Ricci F, Plaxco KW (2009) An electrochemical sensor for the detection of protein-small molecule interactions directly in serum and other complex matrices. J Am Chem Soc 131 (20):6955-6957

137. Kim YS, Niazi JH, Gu MB (2009) Specific detection of oxytetracycline using DNA aptamer-immobilized interdigitated array electrode chip. Anal Chim Acta 634(2):250-254

138. Radi AE, Sanchez JLA, Baldrich E, O'Sullivan CK (2006) Reagentless, reusable, ultrasensitive electrochemical molecular beacon aptasensor. J Am Chem Soc 128(1):117-124

139. Kim YJ, Kim YS, Niazi JH, Gu MB (2010) Electrochemical aptasensor for tetracycline detection. Bioprocess Biosyst Eng 33 (1):31-37

140. de-los-Santos-Alvarez N, Lobo-Castanon MJ, Miranda-Ordieres AJ, Tunon-Blanco P (2007) Modified-RNA aptamer-based sensor for competitive impedimetric assay of neomycin B. J Am Chem Soc 129(13):3808-3809

141. Gonzalez-Fernandez E, de-los-Santos-Alvarez N, Lobo-Castanon MJ, Miranda-Ordieres AJ, Tunon-Blanco P (2011) Impedimetric aptasensor for tobramycin detection in human serum. Biosens Bioelectron 26(5):2354-2360

142. Rowe AA, Miller EA, Plaxco KW (2010) Reagentless measurement of aminoglycoside antibiotics in blood serum via an electrochemical, ribonucleic acid aptamer-based biosensor. Anal Chem 82(17):70907095

143. Freeman R, Li Y, Tel-Vered R, Sharon E, Elbaz J, Willner I (2009) Self-assembly of supramolecular aptamer structures for optical or electrochemical sensing. Analyst 134(4):653-656

144. Xiao Y, Piorek BD, Plaxco KW, Heeger AJ (2005) A reagentless signal-on architecture for electronic, aptamer-based sensors via target-induced strand displacement. J Am Chem Soc 127 (51):17990-17991

145. Du Y, Chen C, Yin J, Li B, Zhou M, Dong S et al (2010) Solidstate probe based electrochemical aptasensor for cocaine: a 
potentially convenient, sensitive, repeatable, and integrated sensing platform for drugs. Anal Chem 82(4):1556-1563

146. Li Y, Qi H, Peng Y, Yang J, Zhang C (2007) Electrogenerated chemiluminescence aptamer-based biosensor for the determination of cocaine. Electrochem Commun 9(10):25712575

147. Sun B, Qi H, Ma F, Gao Q, Zhang C, Miao W (2010) Double covalent coupling method for the fabrication of highly sensitive and reusable electrogenerated chemiluminescence sensors. Anal Chem 82(12):5046-5052

148. Kim YS, Kim JH, Kim IA, Lee SJ, Gu MB (2011) The affinity ratio-its pivotal role in gold nanoparticle-based competitive colorimetric aptasensor. Biosens Bioelectron 26 (10):4058-4063

149. Liu JW, Mazumdar D, Lu Y (2006) A simple and sensitive "dipstick" test in serum based on lateral flow separation of aptamer-linked nanostructures. Angew Chem Int Ed 45 (47):7955-7959

150. Niemeyer C (2001) Nanoparticles, proteins, and nucleic acids: biotechnology meets materials science. Angew Chem Int Ed 40:4128-4158
151. Katz E, Willner I (2004) Integrated nanoparticle-biomolecule hybrid systems: synthesis, properties, and applications. Angew Chem Int Ed Engl 43(45):6042-6108

152. Stoltenburg R, Reinemann C, Strehlitz B (2010) Erkennung von Umweltschadstoffen durch Aptamere. Laborwelt 2:6-9

153. Du Y, Li B, Guo S, Zhou Z, Zhou M, Wang E et al (2011) GQuadruplex-based DNAzyme for colorimetric detection of cocaine: using magnetic nanoparticles as the separation and amplification element. Analyst 136(3):493-497

154. Ma C, Wang W, Yang Q, Shi C, Cao L (2011) Cocaine detection via rolling circle amplification of short DNA strand separated by magnetic beads. Biosens Bioelectron 26(7):3309-3312

155. Huh YS, Erickson D (2010) Aptamer based surface enhanced Raman scattering detection of vasopressin using multilayer nanotube arrays. Biosens Bioelectron 25(5):1240-1243

156. Park H, Paeng IR (2011) Development of direct competitive enzyme-linked aptamer assay for determination of dopamine in serum. Anal Chim Acta 685(1):65-73

157. Walsh R, DeRosa MC (2009) Retention of function in the DNA homolog of the RNA dopamine aptamer. Biochem Biophys Res Commun 388(4):732-735 